\title{
Intergenerational risk-sharing and risk-taking of a pension fund
}

\author{
Christian Gollier ${ }^{1}$ \\ University of Toulouse (IDEI, TSE)
}

January 13, 2007

${ }^{1}$ The author is grateful to Georges de Ménil, Peter Diamond, Jacques Drèze, Andy Posthelwaite, Eytan Sheshinski, Philippe Trainar, Alex White and two anonymous referees for their helpful comments, and to the French Federation of Insurance Companies for its financial support. E-mail: gollier@cict.fr. 


\begin{abstract}
By using their financial reserves efficiently, and thus smoothing shocks on asset returns, pension funds can facilitate intergenerational risk-sharing. In addition to the primary benefit it improved time diversification, this form of risk allocation affords the secondary benefit of allowing the fund to take better advantage of the equity premium, which also favors the consumers. In this paper, our aim is twofold. First, we characterize the socially efficient policy rules of a collective pension plan in terms of portfolio management, capital payments to retirees, and dividend payments to shareholders. We examine both the first-best rules and the second-best rules, where, in the latter case, the fund is constrained by a solvency ratio and by a guaranteed minimum return to workers' contributions. Second, we measure the social surplus of the system compared to a situation in which each generation would save and invest in isolation for its own retirement. One of the main results of the paper is that better intergenerational risk-sharing does not reduce the risk born by each generation. Rather, it increases the expected return to the workers' contributions.
\end{abstract}

Keywords: dynamic portfolio choice, pension, retirement, intergenerational risk sharing, financial intermediation. 


\section{Introduction}

In competitive financial markets, the inability of current generations to share their risks with those who are not born yet makes these markets inefficient. This point was made by Diamond (1977), Gordon and Varian (1988), Ball and Mankiw (2001) and Shiller $(1999,2003)$ among others. In a funded system with individual pension accounts, the absence of any intergenerational sharing of individual portfolio risk implies that workers face high uncertainty on their future pension wealth. In the recent past, many workers had to reduce drastically their standard of living and to work longer after sizeable downturns of financial markets. This inability of markets to allocate risk efficiently across generations has been used to argue in favor of more public intervention, in particular in the form of strenger pay-as-you-go (PAYG) systems. ${ }^{1}$ However, the European experience with PAYG systems tells us that organizing such risk sharing efficiently is subject to a strong political constraint, since current generations are more reluctant to compensate losses than to consume the surpluses of the system. Moreover, the expected return of the PAYG is relatively low compared to the expected return of financial markets.

The United States followed another road with their 1983 Social Security Reforms. The so-called Greenspan Commission reforms involved imposing a mandatory contribution from active baby-boom generations to partially pre-fund their retirements. ${ }^{2}$ These federal trust funds have accumulated almost $\$ 3$ trillion since then. The aim of this paper is to examine how and by how much such a prefunded system can solve the intergenerational risk sharing inefficiency. Such a funded system makes intergenerational risk sharing possible if the trust funds can disconnect generational contributions to generational pension benefits. But this, however, raises the question of which rules should govern these implicit intergenerational cross-subsidizations. It also raises the question of what the funds' assets management strategy should be. These two questions are jointly addressed in this paper.

The properties of ex ante Pareto-efficient rules for intergenerational risk sharing have been examined in several recent papers. For example, Bohn (2003) considers a general equilibrium model of a closed economy and show

\footnotetext{
${ }^{1}$ See for example Aaron, Blinder, Munnell and Orzag (2000), and Burtless (2000).

${ }^{2}$ The United Kingdom and the Netherlands implemented similar prefunded systems.
} 
that governments, by typically promising safe public pensions and issuing safe debt, do not transfer enough risk on the shoulders of current retirees. In the same vein, Krueger and Kubler (2002) show that when returns to physical capital and human capital are imperfectly correlated, the consumption variance of all generations can be reduced by implementing a PAYG system in which pension benefits would be indexed on labor incomes. De Menil, Murtin and Sheshinsky (2006) study ex ante Pareto improving social security reforms when the return of individual saving accounts is uncertain, assuming that transfers only from the young to the old can be implemented. Van Hermert (2005) extends this analysis by considering a model with fourstate correlated risks on human and financial capital. He characterizes the ex-ante Pareto efficient risk sharing rule within a standard PAYG system, together with the households' optimal portfolio allocation.

Contrary to the above-mentioned papers which focus on PAYG systems, Cui, de Jong and Ponds (2005) examine a funded system with a realistic description of risks on financial markets. They compare the welfare implications of various contribution and benefit policies of the fund, together with three equity-bond ratios of the fund's asset allocation. They conclude that funded pension schemes that provide safer and smoother consumption streams are welfare improving compared with pure individual pension schemes. Moreover, the $100 \%$ equity holding strategy of the fund dominates both the 50-50 bond/equity and the $100 \%$ bond strategies.

In this paper, rather than making welfare comparisons of existing policy rules, we optimize jointly on the retirement benefit policy and on the fund's asset allocation strategy. Because we want to characterize operational rules for a collective Defined Contribution (DC) fund, we consider in this paper an OLG model in which each generation contributes to the fund for $n=40$ periods, each period lasting one year. We describe an explicit intergenerational risk sharing mechanism based on a transparent funded pension system, and we measure the social surplus that this system generates compared to a standard individual account DC scheme. Each year, a new generation of workers starts contributing to the fund, and another generation leaves the fund with a pension benefit that is endogenously determined. The pension benefit is contingent on the level of the fund's reserves.

Contrary to most existing papers with the notable exceptions of Cui, de Jong and Ponds (2005) and van Hemert (2005), the choice of the portfolio is endogenous to the model, and can be made contingent on the fund's reserves. 
Another important difference with the existing literature is that we assume that the government delegates the management of the scheme to a trust fund controlled by shareholders. The shareholders bring equity to the fund when it is created in exchange for future dividends. This deal is governed by a participation constraint from the viewpoint of shareholders. By providing capital to the system, the trust fund is able to offer portfolio insurance to workers that takes the form of a minimum return to their savings. The problem is to determine for each year and for each contingency, the optimal portfolio of assets, the payment of benefits to the new pensioners, and the distribution of dividends to the shareholders of the insurance company. The trust fund is constrained by a solvency ratio, which guarantees that the current market value of assets is always larger than the current market value of the minimum liabilities to the contributing workers. The existence of such a constraint has two central consequences. First, it reduces the ability of the funded scheme to transfer risk to future generations. Second, it makes the problem analytically intractable. As a, our results rely on a numerical optimization procedure.

The most important message of this paper is that a better intergenerational risk sharing scheme makes it socially efficient to raise the collective risk exposure in order to take advantage of the large equity premium. When risks are exogenous, the only benefit of intergenerational risk- sharing is to make pension benefits safer, without changing the mean performance of savings. In our model, risks are endogenous since the fund has the freedom to reallocate its reserves between a risk free asset and a risky asset. The reform raises the demand for equity. This additional collective risk exposure is only partially offset by the better diversification. We then obtain the paradoxical property that the better risk-sharing scheme raises the risk born by each generation! Rather, the benefit of the reform comes from the larger expected pension benefit offered to all current and future generations. In order to elucidate this property, we consider a very simple two-period model in section 2 .

Concerning the properties of the efficient management of the fund, we can summarize our main findings as follows. First, the share of the fund's wealth invested in the risky asset is an inverted U-shaped function of the fund's cashin-hand. Compared to the well-known Merton-Samuelson optimality rule of a wealth-independent investment share in the risky asset, two additional effects must be taken into account in our context. The first one is due to the solvency issue, which forces the fund to drastically reduce its portfolio risk 
after a loss, when the solvency constraint becomes an issue. This explains why the share of the fund's financial reserves invested in the risky asset is increasing with respect to low wealth levels. The second one comes from the existence of the flow of future contributions which can be seen as a risk free asset in the fund's balance sheet. In order to maintain constant the share of the risky asset in the fund's total wealth as stated by the Merton-Samuelson rule, the fund should invest relatively more in the risky asset at low levels of cash-in-hand, and it should rebalance its portfolio in favor of the risk free asset when the level of cash-in-hand increases.

Second, the benefit distributed to new pensioners is increasing and concave in the market value of the fund's assets. When solvency is an issue, the distributed benefit above the contractual minimum is very sensitive to the financial situation of the fund, which means that intergenerational risk sharing does not work well in these circumstances. On the contrary, when the fund is wealthy, the benefit distributed to the new pensioners is much less sensitive to shocks on the market value of the fund's assets. Two lessons are derived from this observation. First, the intergenerational sharing of risk is possible only when the fund has enough wealth to smooth financial shocks across different generations of workers. The initial ratio of assets to liabilities of the fund is a crucial aspect of this problem, which can be alleviated by shareholders' initial equity funding. Second, the efficient share of risk that should be born by retirees depends upon the financial health of the fund. This second conclusion differs greatly from the conclusion obtained in a standard PAYG system in which there is no solvency issue. Indeed, when there is no such issue, the efficient share of the aggregate risk that should be born by retirees is independent of the history of past shocks.

We also measure the welfare gain of the improved risk sharing in the economy. In order to perform this welfare analysis, we compare three long term saving schemes. The first saving scheme, which is presented in section 3 , is based on personal retirement accounts. Workers determine their optimal portfolio risk in each period of their life, knowing that there will be no solidarity across generations in the case of a financial downturn. We show that it is optimal in this case for workers to invest a share of the balance of their pension account that is decreasing with their age. Following this dynamically optimal strategy yields a great deal of uncertainty regarding the final level of retirement wealth, opening the door to useful intergenerational 
risk-sharing scheme. ${ }^{3}$ Assuming a risk free rate of $2 \%$ and a stocks' excess expected return of $3.9 \%$, we show that following this optimal dynamic portfolio strategy is equivalent in terms of expected utility of pension wealth to a sure investment of lifetime savings at an interest rate of $3.33 \%$.

The second long term savings scheme examined in section 4 yields a firstbest intergenerational risk sharing. It maximizes a discounted sum of the expected utility of future generations subject to an intertemporal budget constraint. It minimizes the solvency issue by just constraining the market value of the fund's assets to be nonnegative. The first-best solution is thus quite unrealistic, but it is useful for measuring the maximum social surplus of intergenerational risk-sharing. The first-best strategy consists in investing a constant share of the fund's total wealth in the risky asset, and to distribute a constant share of the fund's total wealth to retirees. The fund's total wealth is the sum of the current financial reserves and the net present value of future workers' contributions. The first-best solution yields a level of intergenerational welfare that is equivalent to the one that would be obtained by investing pension savings at a risk-free interest rate of $4.39 \%$. Compared to autarky, this represents a $30 \%$ increase in the certainty equivalent of the pension benefits paid to all current and future generations. ${ }^{4}$ This shows the potentially large welfare gain of intergenerational risk-sharing.

However, the main problem of the first-best solution is the possible fast exhaustion of the financial reserves of the scheme and the potential resistance of future generations to participate to the scheme as a consequence of such circumstances. This is why in section 5 , we examine in section 5 the more realistic second-best pension scheme in which the pension fund is constrained by a solvency ratio and by the requirement of a minimum rate of return of $0 \%$ to its members. The second-best scheme yields an intergenerational welfare that is equivalent to a $3.83 \%$ sure rate of returns on savings. This still represents a $12.7 \%$ increase in the certainty equivalent pension benefits

\footnotetext{
${ }^{3}$ Poterba, Rauh, Venti and Wise (2003) evaluate the risk to retirement wealth of the $100 / 0,50 / 50$ and 0/100 age-independent allocation strategy in 401(k) plans, using a stochastic simulation algorithm. They conclude that the $100 \%$ investment in equity over the entire lifetime makes pension wealth very uncertain but optimal (if the investor has some non-401(k) wealth) because of the large equity premium.

${ }^{4}$ When considering intergenerational risk sharing, the relevant concept of efficiency is that of ex-ante Pareto-efficiency. See Demange and Laroque (1999) and Demange (2002) for other concepts of efficiency with overlapping generations.
} 
compared to autarky. ${ }^{5}$

\section{The surplus of risk sharing when risks are endogenous: A simple model}

In order to evaluate the social surplus of intergenerational risk sharing, let us consider a very stylized model with two agents. They have the same von Neumann-Morgenstern utility function $u(z)=z^{1-\gamma} /(1-\gamma)$, where $\gamma$ is the index of relative risk aversion. The initial wealth of agent $i, i=1$ or 2 , is denoted $w_{i}$. Agent $i$ can invest in two assets, one being risk free with a zero return, and the other being risky with return $\widetilde{x}_{i}$. We assume that $\widetilde{x}_{1}$ and $\widetilde{x}_{2}$ are independent and identically distributed with mean $\mu>0$ and variance $\sigma^{2}$. In autarky, each agent selects the dollar investment $\alpha$ that maximizes the expected utility of final wealth:

$$
\max _{\alpha} E u\left(w_{i}+\alpha \widetilde{x}_{i}\right) \simeq u\left(w_{i}+\alpha \mu-\frac{1}{2} \frac{\gamma}{w_{i}} \alpha^{2} \sigma^{2}\right) .
$$

Suppose that the portfolio risk is small, so that the Arrow-Pratt approximation can be applied. Obviously, the solution of this program is:

$$
\alpha_{i}=\frac{\mu}{\gamma \sigma^{2}} w_{i}
$$

Plugging this solution into (1), we can evaluate the certainty equivalent payoff of the optimal portfolio as

$$
C E Q_{i}=\alpha_{i} \mu-\frac{1}{2} \frac{\gamma}{w_{i}} \alpha_{i}^{2} \sigma^{2}=\frac{1}{2} \frac{\mu^{2}}{\gamma \sigma^{2}} w_{i}
$$

As a first step in measuring the social surplus of risk sharing, let us assume that the two agents decide to share risk $\widetilde{x}_{1}$ efficiently, the individual risk exposure $\alpha_{i}$ being fixed at their autarky level. Given our small risk assumption, such risk transfer can be characterized by a linear function $t\left(x_{1}\right)=t_{0}+\eta \alpha_{1} x_{1}$ that determines the transfer from agent 1 to agent 2 as

\footnotetext{
${ }^{5}$ Given the differences in the modeling strategies, this estimation is reasonably comparable to the one by van Hemert (2005), who estimated the welfare surplus to be $5.14 \%$ of the consumers' human capital.
} 
a function of the realization of $\widetilde{x}_{1}$. Again using Arrow-Pratt approximations, we get that the social surplus associated with bearing of risk $\alpha_{1} \widetilde{x}_{1}$ equals

$$
\begin{aligned}
C E Q(\eta) & =\alpha_{1} \mu-\frac{1}{2} \frac{\gamma}{w_{1}}(1-\eta)^{2} \alpha_{1}^{2} \sigma^{2}-\frac{1}{2} \frac{\gamma}{w_{2}} \eta^{2} \alpha_{1}^{2} \sigma^{2} \\
& =\frac{\mu^{2}}{\gamma \sigma^{2}}\left\{w_{1}-\frac{1}{2}\left[w_{1}(1-\eta)^{2}+\frac{w_{1}^{2}}{w_{2}} \eta^{2}\right]\right\} .
\end{aligned}
$$

The optimal risk sharing rule $\eta^{*}$ is the one that maximizes $C E Q(\eta)$. It is easy to check that the optimal sharing $\eta^{*}$ equals $w_{2} /\left(w_{1}+w_{2}\right)$, and that the maximum social surplus equals

$$
C E Q\left(\eta^{*}\right)=C E Q_{1} \frac{w_{1}+2 w_{2}}{w_{1}+w_{2}} .
$$

When the two agents have the same wealth, the certainty equivalent payoff associated with investment in $\widetilde{x}_{1}$ is increased by $50 \%$.

But there is an additional benefit to extract from the efficient risk sharing, since the ability to pool risk $\widetilde{x}_{1}$ across agents should induce them to accept more of that risk. To explore this question, let us assume that the two agents determine simultaneously how much risk to undertake and how to share it:

$$
\max _{\alpha, \eta} C E Q(\alpha, \eta)=\alpha \mu-\frac{1}{2} \frac{\gamma}{w_{1}}(1-\eta)^{2} \alpha^{2} \sigma^{2}-\frac{1}{2} \frac{\gamma}{w_{2}} \eta^{2} \alpha^{2} \sigma^{2}
$$

It is easy to check that the optimal solution of this problem is still $\eta^{*}=$ $w_{2} /\left(w_{1}+w_{2}\right)$ and

$$
\alpha^{*}=\frac{\mu}{\gamma \sigma^{2}}\left(w_{1}+w_{2}\right)
$$

Observe that the demand for the transferable risk $\widetilde{x}_{1}$ is increased compared to autarky. The ability of the two agents to share a given risk increases the demand for that risk. Sot, it is as if the agent's wealth that was originally protected form risk had been transferred to the initial risk-bearer. Equivalently, it is as if agent 2 would have a direct access to the investment on risk $\widetilde{x}_{1}$ through the efficient risk-sharing scheme with agent 1 . Notice also that agent 1 increases the demand for his risky asset by a factor $\left(w_{1}+w_{2}\right) / w_{1}$, but because he retains only a fraction $w_{1} /\left(w_{1}+w_{2}\right)$ of the risk, he ends up with exactly the same risk exposure. On the other side, agent 2 retains the same exposure on $\widetilde{x}_{2}$ and accepts some risk from agent 1 , thereby bearing 
more risk than in autarky. In fact, everything works as if agent 2 were to subrogate the purchase of $\alpha_{2}$ units of risk $\widetilde{x}_{1}$ to agent 1 . Agent 1 purchases this optimal amount of risk $\widetilde{x}_{1}$ and transfers it to agent 2 through the agreedupon risk-sharing scheme. Globally, the better sharing of risk in the economy induces everyone to end up with at least as much risk as in autarky. Still, the social surplus is positive since we have that

$$
C E Q\left(\alpha^{*}, \eta^{*}\right)=C E Q_{1} \frac{w_{1}+w_{2}}{w_{1}} .
$$

The social surplus of the $\widetilde{x}_{1}$ risk-taking opportunity is increased by a factor $\left(w_{1}+w_{2}\right) / w_{1}$. For two equally wealthy agents, this is a $100 \%$ increase in surplus. The benefit of the risk sharing is not to reduce risk, but rather to increase the expected payoff from the risky investment. Our main finding in this section is that the ability to diversify risk induces people to accept more risk so that only part of the additional risk is offset by diversification. In short, when individual risks are endogenous, the access to risk sharing leads people to increase their expected wealth, not to reduce their risk!

The easiest application of this model is to the international diversification of individual portfolios, where $i=1$ and $i=2$ are two countries with independent economic growth processes. In the context of this paper however, $i=1$ and $i=2$ are two disconnected periods, where the growth process of the economy exhibits no serial correlation. The risk-sharing in that context takes a form of whereby the earlier generation contributes to the economy's aggregate capital accumulation by consuming less than its net production, in order for the future generation to consume more than what it will produce. Of course, this transfer can be contingent only upon the information available during the lifetime of the first generation. Thus, the first generation cannot bear some share of the second generation's risk, which implies that only risk $\widetilde{x}_{1}$ can be shared. When we consider a specific (pension) fund to serve as a medium for these intergenerational transfers, the sharing of risk across generations is limited by the solvency of the fund. This is the central issue analyzed in this paper.

\section{Optimal individual saving accounts}

The economy is composed of overlapping generations of a fixed size that is normalized to unity. Each generation contributes to a pension fund during 
$n=40$ years. The yearly contribution $y$ is paid out by the active workers at the beginning of the year. We are in a context of defined contributions, which implies that $y$ is exogenous to the model. At the end of the $n$th year, the old generation receives a benefit whose level is endogenous to the model. This retiring generation is replaced by a young generation which starts contributing to the fund. This means that $n$ contributing generations coexist in the fund, which receives ny monetary units at the end of each period. The welfare of a generation is measured by the expected utility that it obtains from consuming the pension benefit at the retirement age. The workers' utility function $u$ is increasing and concave in the pension benefit $b$.

There are two financial assets in the economy, one of which is risk-free. Asset returns are unpredictable. The gross yearly return of the risk free asset is constant over time and is equal $R$. In our calibration, we consider an interest rate of $2 \%(R=1.02)$. The excess return of the risky asset in year $t$ is denoted $\widetilde{x}_{t}$. There is no serial correlation of returns over time, so that $\widetilde{x}_{1}, \widetilde{x}_{2}, .$. are independent and identically distributed. $R$ and $\widetilde{x}$ are exogenous. In particular, we assume that they are not affected by the architecture of the pension system, as would be the case in a small open economy. We calibrate our model with the empirical distribution of the real yearly return of the SP500 in excess of the risk-free rate over the period 1963-1994. The expected real excess return is $E \widetilde{x}=\mu=3.9 \%$, and the standard deviation is $\sigma_{x}=13.6 \%$.

As a benchmark, we examine an economy in which there is no risk sharing. The fund can be interpreted in that case as a collection of $n$ individual saving accounts. In this model, each generation can be considered in autarky. At the beginning of each of the $n$ contribution years, the generation has to determine how much of its reserves to invest in the risky asset with the rest being invested in the risk-free asset. Let $\alpha_{t}$ denote the monetary investment in the risky asset at the beginning of the $t^{t h}$ contribution year, $t=1, \ldots, n$. The financial reserve of a generation from contribution year $t-1$ to contribution year $t$ is denoted $w_{t}$. The individual dynamic portfolio problem can be written as

$$
\begin{aligned}
& U^{a u t}=\max _{\alpha_{1}, \ldots, \alpha_{n}} E u(\widetilde{b}) \\
\text { s.t. } w_{1}= & 0 ; \\
w_{t+1}= & R\left(w_{t}+y\right)+\alpha_{t} \widetilde{x}_{t}, \quad t=1, \ldots, n ;
\end{aligned}
$$




$$
\widetilde{b}=w_{n+1} .
$$

In this paper, we assume that workers have constant relative risk aversion equaling $\gamma$, so that $u(b)=b^{1-\gamma} /(1-\gamma)$. We take a relatively conservative position by assuming that $\gamma=5 .{ }^{6}$ In that case, the solution to this dynamic portfolio problem is well-known since Merton (1969) and Samuelson (1969). It is described in the following proposition.

Proposition 1 The optimal dynamic portfolio strategy of an individual saving account is such that

$$
\alpha_{t}=a^{\text {aut }}\left(w_{t}+h_{t}\right), \quad \text { with } \quad a^{\text {aut }}=a^{*} R
$$

for $t=1, \ldots, n$, where $w_{t}$ is the value of the portfolio at the beginning of period $t, h_{t}=\sum_{i=0}^{n-t} R^{-i} y$ is the residual net present value of future contributions, and $a^{*}$ is the unique positive solution of the equation $E \widetilde{x}\left(1+a^{*} \widetilde{x}\right)^{-\gamma}=0$. When measured from the beginning of the first period, the optimal expected utility at retirement age equals

$$
U^{a u t}=\left[R^{1-\gamma} E\left(1+a^{*} \widetilde{x}\right)^{1-\gamma}\right]^{n} \frac{\left(\sum_{i=0}^{n-1} R^{-i} y\right)^{1-\gamma}}{1-\gamma} .
$$

Proof: See Appendix 1.

The optimal investment in the risky asset at any time $t$ is a constant proportion $a^{*} R$ of the household's total retirement wealth, which is defined as the sum of the value $w_{t}$ of the portfolio and of the residual Net Present Value (NPV) of the future contributions. This reflects the well-known fact that myopia is optimal under constant relative risk aversion: the time horizon has no effect on the share of the investor's total wealth to be invested in the risky asset. For the numerical value of our benchmark case, we estimate that $a^{*}=39.6 \%$, so that the optimal share of the total retirement wealth to be permanently invested in the risky asset is $2 \%$ larger, i.e., $a^{a u t}=40.4 \%$.

Notice that the share of the current balance of the individual account invested in the risky asset equals

$$
\frac{\alpha_{t}}{w_{t}}=a^{a u t}\left(1+\frac{h_{t}}{w_{t}}\right) .
$$

\footnotetext{
${ }^{6}$ This implies that workers are ready to pay as much as $2.4 \%$ of their wealth to eliminate a fifty-fifty risk to gain or loose $10 \%$ of their wealth.
} 
It is usually decreasing with age, since the balance $w_{t}$ of the pension account will be typically increasing with age, whereas the NPV, $h_{t}$, of future contributions is decreasing with age. Thus, whereas it is optimal to invest a constant share of total pension wealth in equity, it is usually optimal to reduce the share of current financial wealth invested in equity when approaching retirement age. This argument has been proposed by Bodie, Merton and Samuelson (1992) to justify the standard recommendation to reduce portfolio risk when growing older. ${ }^{7}$

When following this optimal investment strategy, the retirement wealth is distributed as

$$
\widetilde{b}=R^{n} h_{1} \prod_{t=1}^{n}\left(1+a^{*} \widetilde{x}_{t}\right) .
$$

Using this equation, one can check that the expected retirement wealth is thus equal to $R^{n}\left(1+a^{*} \mu\right)^{n} h_{1}=113.7 y$, whereas the standard deviation of retirement wealth equals $R^{n}\left[\left(E\left(1+a^{*} \widetilde{x}\right)^{2}\right)^{n}-\left(1+a^{*} \mu\right)^{2 n}\right] h_{1}=39 y$.

Proposition 1 also gives us the expected utility $U^{\text {aut }}$ of the retirement capital in autarky, as measured when the household starts to save. We define the certainty equivalent final wealth $B^{\text {aut }}$ as the sure pension wealth that yields the same expected utility for the retiree as the random pension wealth $\widetilde{b}$ that is obtained by following the optimal portfolio strategy (6): $u\left(B^{\text {aut }}\right)=U^{\text {aut }}$. We obtain

$$
B^{\text {aut }}=R^{n}\left[E\left(1+a^{*} \widetilde{x}\right)^{1-\gamma}\right]^{\frac{n}{1-\gamma}} \sum_{i=0}^{n-1} R^{-i} y .
$$

In our benchmark case, we obtain $B^{\text {aut }}=84.1 y$. The constant flow of saving optimally invested in financial markets over the $n=40$ years preceding retirement yields the same expected utility for the retiree as receiving an amount of capital 84 times the yearly saving rates at retirement age. This means that the psychological cost of risk - or the risk premium - equals 29.6y. We can also define the certainty equivalent rate of return on saving as the interest rate $r^{\text {aut }}$ on saving that yields the expected utility $U^{\text {aut }}$ :

$$
u\left(\sum_{t=1}^{40} y\left(1+r^{a u t}\right)^{t}\right)=U^{a u t}
$$

\footnotetext{
${ }^{7}$ Other arguments for and against a decreasing age-profile of the optimal assets allocation are discussed in Gollier (2005).
} 
Under our numerical specification, we obtain a certainty equivalent rate of return $r^{\text {aut }}=3.33 \%$. The ability to invest in stocks raises the certainty equivalent rate of return on savings from the risk-free rate of $R-1=2 \%$ to $3.33 \%$. This return is still far away from the expected rate of equity, which is assumed in our calibration to be equal to $5.9 \%$.

To end this section, observe that the optimal investment strategy is difficult to implement when credit markets are inefficient. Indeed, at the beginning of his first year of contribution, the worker should invest $a^{a u t} h_{1}=11.27 y$ in the risky asset, whereas he has only $y$ on his pension account at that time. This means that implementing the optimal strategy would require the worker to borrow more than 10 times his current pension balance to invest in equity. Because this is unrealistic, we consider a constrained version of program (5) where we add the constraint that the investment in the risky asset can never exceed the current balance of the pension account: $\alpha_{t} \leq w_{t}+y, \quad t=1, \ldots, n$. A simple (myopic) rule-of-thumb is that the worker invest the unconstrained optimum $\alpha_{t}=a^{*} R\left(w_{t}+h_{t}\right)$ as long as the no-borrowing constraint is not binding, and to be $100 \%$ in equity when it is binding: ${ }^{8}$

$$
\alpha_{t}=\min \left(a^{a u t}\left(w_{t}+h_{t}\right), w_{t}+y\right) .
$$

The no-borrowing constraint is likely to be binding early in the consumers' contribution period of consumers, and to be slack once the worker has accumulated enough financial reserves in his pension account. We estimated numerically the certainty equivalent pension wealth and the certainty equivalent return of this individual pension saving. We got respectively $B^{\text {aut }}=81.9 y$ and $r^{\text {aut }}=3.23 \%$. These values are not significantly different from the unconstrained case.

It appears that the uncertainty on the final wealth available to the retiree is large, in spite of the important rebalancement of portfolios in favor of the risk-free asset as investors get closer to retirement. In order to measure the riskiness of the pension wealth at retirement age in autarky, we performed

\footnotetext{
${ }^{8}$ We are aware of the fact that this myopic strategy is not the optimal one under the noborrowing constraint, as shown by Grossman and Vila (1992). Even if the constraint is not binding today, the risk that it could bind in the future has an effect on the optimal current portfolio allocation. However, given the fast decreasing NPV $h_{t}$ of future contributions, the probability of this event occurring is small. Indeed, we solved numerically the constrained version of the program and found no difference between the optimal solution and the rule-of-thumb strategy.
} 
a simulation of 100,000 random scenarios of $n$ years of yearly performances of the equity market. Our findings are summarized in Figure 1, where we draw the frequency table of final pension wealth. The smallest and the largest pension wealth levels in these scenarios have been $28.12 y$ and $446.7 y$, respectively, with an average value of $103.7 y$ and a standard deviation of 32.1y. The upper limit on the share of wealth that can be invested in the risky asset decreases with both the mean and the standard deviation of the retirement wealth.

\section{INSERT FIGURE 1 AROUND HERE}

This shows that there is ample room for intergenerational risk sharing in this economy. It is noteworthy that, as explained by Samuelson (1963), there is no time-diversification of the portfolio risk going on in this personal retirement system. The portfolio risk taken in year 1 is not diversified away by the portfolio risk taken over the $n-1$ remaining years. Diversification could exist here only through an intergenerational scheme, in which one generation exchanges half of its lifetime portfolio risk with half of the portfolio risk borne by another (distant) generation.

\section{First-best intergenerational risk sharing}

In this section, we consider the viewpoint of a hypothetical social planner who is strong enough to commit all future generations to contribute to a collective Defined Contribution pension system. We thus abstract from any consideration about the potentially opportunistic behavior of future generations. In short, we will characterize a first-best solution. Our aim here is to estimate the maximum welfare gain that can be attained through intergenerational risk sharing. Of course, this first-best solution is unrealistic. This is why we will consider a second-best solution in the next section.

Suppose that at time $t=0$, the $n$ current generations agree to transfer their individual saving accounts to a pension fund that would be allowed to reallocate risks across generations. Let $Y_{0}$ denote the value of this initial transfer. It depends upon the realized returns of the risky asset during the last $n$ years. We hereafter assume that $Y_{0}$ equals the average wealth accumulated 
by the different generations coexisting in year $t=0$, so that

$$
Y_{0}=\sum_{t=1}^{n} E w_{t},
$$

where $E w_{t}$ is the expected wealth accumulated by the generation in contribution year $t$ in autarky. Using the model of the previous section, we obtained numerically that $Y_{0}$ equals $1638 y$. In this section, we assume that contributions to the fund by future generations are compulsory. The net present value of these future contributions equals

$$
K=\sum_{t=0}^{\infty} R^{-t} n y=\frac{n y R}{R-1} .
$$

In our calibration, we obtain that $K$ equals $2040 y$.

Let $w_{t}$ be the market value of all assets owned by the fund at the end of year $t-1$. At the beginning of year $t$, the fund collects the savings $y$ of the $n$ contributing generations. It also distributes the benefit $b_{t}$ to the generation which just retired at the end of the previous period. As before, $\alpha_{t}$ is the money investment in the risky asset by the fund in year $t$. In Figure 2, we represented these flows in year $t$.

INSERT FIGURE 2 AROUND HERE

We measure the social welfare of the overlapping generations of workers by the discounted sum of the flow of expected utility generated by consuming their pension wealth at retirement. Consider the decision problem of the fund at the beginning of period 0 . We look for the dynamic contingent strategy of the fund, both in terms of the distribution $b$ and the portfolio management $\alpha$ that maximize the welfare of the overlapping generations of workers:

$$
U^{f b}=\max E\left[\sum_{t=0}^{\infty} \beta^{t} u\left(\widetilde{b}_{t}\right)\right]
$$

subject to

$$
\begin{aligned}
w_{0} & =Y_{0} \\
w_{t+1} & =R\left(w_{t}-b_{t}+n y\right)+\alpha_{t} \widetilde{x}_{t}, \quad \forall t \geq 0 ; \\
w_{t}+K & \geq 0, \quad \forall t \geq 1,
\end{aligned}
$$


with $w_{0}=Y_{0}$, and where $\beta$ is the discount factor used by the social planner to weight the welfare of the different generations. Observe that we allow the fund to value the flow of future contributions, so that the market value of all "assets" of the fund equals $w_{t}+K$, which is constrained to be nonnegative. It happens that the solution of this program is well-known.

Proposition 2 The first-best benefits distribution and assets allocation are such that

$$
b^{f b}(w)=m(w+K) \text { with } m=1-\left(\beta R^{1-\gamma} E\left[1+a^{*} \widetilde{x}\right]^{-\gamma}\right)^{1 / \gamma},
$$

and

$$
\alpha^{f b}(w)=a^{f b}(w+K), \text { with } a^{f b}=R(1-m) a^{*},
$$

where $a^{*}$ solves $E \widetilde{x}\left(1+a^{*} \widetilde{x}\right)^{-\gamma}=0$. Moreover, the expected growth rate of the fund's financial wealth constant and equal to

$$
\frac{E\left[w_{t+1}+K \mid w_{t}\right]}{w_{t}+K}=R(1-m)\left(1+a^{*} \mu\right)
$$

When measured from the date at which the reform takes place, the intergenerational welfare equals

$$
U^{f b}=\frac{m^{-\gamma}\left(Y_{0}+K\right)^{1-\gamma}}{1-\gamma}
$$

Proof: See Appendix 2.

The optimal strategy of the fund is characterized by two policy functions $b$ and $\alpha$ such that $b_{t}=b\left(w_{t}\right)$ and $\alpha_{t}=\alpha\left(w_{t}\right)$. These two functions can be interpreted as an explicit contract among the different generations that stipulates how much risk will be accepted, and how these risks will be allocated over time. We see that these functions are linear with the market value $w_{t}$ of fund's assets. In fact, both the pension benefit and the risky investment can be expressed as constant shares of the fund's aggregate wealth, which includes both the value $w_{t}$ of the financial assets and the NPV $K$ of the promised future contributions to the fund. As proposed for example by Valdés-Prieto (2005), the idea is to explicitly include this additional asset in the balance sheet of the fund by securitizing the flow of future contributions on financial markets. 
The only parameter that remains to be selected is the discount factor $\beta$, which governs the relative generosity of the system between current and future generations. Observe that the choice of $\beta$ influences the share $m$ of the aggregate wealth of the fund to be distributed to the current retirees. A larger $\beta$ implies a smaller $m$, and a larger growth rate of the fund's expected wealth to be distributed to future generations. We propose to choose $\beta$ in order that the growth rate of the fund's wealth be exactly zero in expectation, thereby being "fair" across generations. Combining equations (13) and (15), we obtain that

$$
\beta=\left[R\left(1+a^{*} \mu\right)^{\gamma} E\left(1+a^{*} \widetilde{x}\right)^{-\gamma}\right]^{-1} .
$$

In our calibration exercise, this means that $\beta=0.9374$. This implies that the aggregate wealth of the fund follows a martingale, and the financial shocks on its reserves are permanent. ${ }^{9}$ This also implies that all present and future generations have the same expected retirement benefit conditional on the information available at the time of the reform.

Every year, the fund should distribute to the retiring generation a constant share $m=3.43 \%$ of the aggregate fund's wealth. This means for example that a generation bears only $3.43 \%$ of the portfolio risk taken by the fund the year before this generation retires, thereby illustrating the intergenerational risk sharing of the scheme. The optimal portfolio strategy is to invest a constant share $a^{f b}=R(1-m) a^{*}=39.0 \%$ of the fund's aggregate wealth in the risky asset. ${ }^{10}$ Because the aggregate wealth includes the net present value $K$ of the flow of future contributions, this implies that the demand for risky assets is much increased by the improved intergenerational risk sharing arrangement. This is perfectly in line with the conclusion of Section 2, where we showed that the efficient sharing of risk has the same effect on the demand for equity as the transfer of wealth of the future generations to the current ones. Under the system of individual pension accounts presented in the previous section, we have estimated numerically the av-

\footnotetext{
${ }^{9}$ For any $\beta$ larger than 0.9374 , the social planner will take advantage of the large assets returns by accumulating more reserves over time. The wealth of the pension fund would therefore be non-stationary.

${ }^{10}$ The difference between $a^{a u t}=40.4 \%$ and $a^{f b}=39 \%$ just comes from the fact that, in the first-best solution, the fund must pay an immediate benefit to the retiring generation. If we base our computations on the fund's after-benefit-payment wealth, we would have that the share of aggregate wealth to be invested in equity would be exactly the same in the two cases: $a^{*} R=40.4 \%$.
} 
erage demand for the risky asset,and we obtained $E\left[\sum_{t=1}^{n} \alpha_{t}^{a u t}\right] \simeq 932.7 y$. The day the reform is implemented, the demand for the risky asset jumps to $\alpha^{f b}\left(Y_{0}+K\right)=1434.4 y$. This represents a $54 \%$ increase in the demand for the risky asset. Because risks are better diversified in the economy, it is socially efficient to accept more risk in the economy.

Conditionally on the information available at the date of the reform, the retirement benefit paid to the generation retiring at date $t$ is distributed as

$$
\widetilde{b}_{t}=m\left(Y_{0}+K\right) R^{t}(1-m)^{t} \prod_{i=1}^{t}\left(1+a^{*} \widetilde{x}_{i}\right) .
$$

As mentioned earlier, because of our choice of $\beta$, the mean of $\widetilde{b}_{t}$, which equals $m\left(Y_{0}+K\right)=126.2 y$, is time-independent. On the contrary, its standard deviation $m\left(Y_{0}+K\right) R^{t}(1-m)^{t}\left[\left(E\left(1+a^{*} \widetilde{x}\right)^{2}\right)^{t}-\left(1+a^{*} \mu\right)^{2 t}\right]$ is growing with the time horizon. For example, the young generation entering the labour market just at the time of the pension reform and retiring in 40 years faces a standard deviation equaling 43.6y, and this number goes up to $54.1 y$ for the generation that will retire 20 years after, in 60 years. In Figure 3, we have drawn the empirical distributions of the pension benefits paid to these two generations. These results should be compared to the case of autarky, in which the mean pension wealth is $105.8 y$, and its standard deviation is $39 y$. These results are in line with the properties of the simple risk sharing model that we developed in Section 2. Namely, the benefit of the intergenerational risk sharing does not translate into less risk borne by each generation. Rather, the intergenerational sharing of risk induces an increase in the demand for the risky asset, thereby increasing the expected return of their portfolio and the overall performance of the pension fund.

INSERT FIGURE 3 AROUND HERE

Finally, using (16), we can measure the impact of the first-best intergenerational risk sharing scheme on intergenerational welfare. As in the previous section, it is easier to measure the certainty equivalent constant benefit $B^{f b}$ distributed to all future generation that yields the same intergenerational welfare: $U^{f b}=u\left(B^{f b}\right) /(1-\beta)$. In our calibration, we obtain $B^{f b}=108.8 y$, a benefit that should be compared to what generations obtain in autarky, $B^{a u t}=84.1 \mathrm{y}$. The first-best solution yields a social surplus which is equivalent to a $29 \%$ increase in the benefits paid to all future generations of pensioners. In terms of the certainty equivalent interest rate on savings, using 
a formula equivalent to (8), we obtain that $r^{f b}=4.39 \%$. This is a considerable increase compared to the certainty equivalent interest rate obtained in autarky: $r^{\text {aut }}=3.23 \%$.

However, this social surplus is not shared equally among the future generations. Indeed, seen from the day of the reform, all future generations enjoy the same expected pension benefit, but the generations living in the distant future face a larger uncertainty about their pension benefit than the current generations. It implies that the reform is in fact relatively more favorable to the current generations, given their risk aversion. To see this, we can define the certainty equivalent $b_{t}^{f b}$ of the generation retiring at date $t$, conditional on the information available at date $t=0$, as $u\left(b_{t}^{f b}\right)=E u\left(\widetilde{b}_{t}\right)$. Using equation (17), we obtain that

$$
b_{t}^{f b}=q^{t} b_{0}^{f b} \text { with } q=R(1-m)\left(E\left(1+a^{*} \widetilde{x}_{i}\right)^{1-\gamma}\right)^{\frac{1}{1-\gamma}}
$$

and $b_{0}^{f b}=m\left(Y_{0}+K\right)$. We obtain $q=0.9926$ with the value of our parameters. This means that, seen from $t=0$, the certainty equivalent pension benefit decreases at a rate of $0.75 \%$ per year. This implies that the reform makes generations living in the very distant future ex-ante worse off, and the reform is therefore not ex-ante Pareto-improving. ${ }^{11}$

As is usual in most dynamic risk sharing arrangements, there is a possible commitment problem. Because of the large portfolio risk taken by the fund, successive adverse shocks on financial markets can dramatically reduce the funds' reserves in such a way that young workers may prefer to switch back to an individual pension system. To examine this question, we determine the certainty equivalent pension benefit $b^{f b}(w)$ for a young worker who starts contributing to the system in year $t$ given the financial reserve $w$ of the fund at that date:

$$
\begin{aligned}
u\left(b^{f b}(w)\right) & =E\left[u\left(\widetilde{b}_{t+n}\right) \mid w_{t}=w\right] \\
& =m^{1-\gamma}\left[R^{1-\gamma}(1-m)^{1-\gamma} E\left(1+a^{*} \widetilde{x}\right)^{1-\gamma}\right]^{n} \frac{(w+K)^{1-\gamma}}{1-\gamma} .
\end{aligned}
$$

A commitment problem arises for the young generation entering into the system if $b^{f b}(w)$ is smaller than the certainty equivalent pension in autarky

\footnotetext{
${ }^{11}$ The ex-ante Pareto-superiority of the reform would require selecting a larger discount factor $\beta$. But that would imply that the fund's reserves would increase without bound in expectation.
} 
$B^{a u t}=84.1 y$. We derived numerically that this happens when reserves $w$ are smaller than $1250 y$. In spite of the fact that the initial reserves $Y_{0}=1638 \mathrm{y}$ much larger than this minimum, such a situation is quite likely to occur at the same point in the future. For example, based on a simulation over 100000 random scenarios, we estimated that the probability that the level of reserves $w_{40}$ be smaller than $1250 y$ forty years after the reform is $42 \%$.

\section{Second-best intergenerational risk sharing}

The first-best intergenerational risk sharing scheme is hardly politically sustainable if a succession of negative shocks on financial markets arises early in the life of the fund. In particular, the fund may need to offer a negative return on contributions in order to restore its future attractiveness in the future. In this section, we add a few additional constraints to the system in order to make it less sensitive to this political sustainability problem.

\subsection{The second-best constraints}

The key additional element that we add in the system is a constraint on the minimum return that must be given to workers. The fund guarantees a minimum gross return $R_{\min }$ to workers on their savings. This guaranteed minimum return of the fund can be interpreted as a portfolio insurance scheme. It implies that the minimum benefit paid to the new retirees is

$$
b_{\min }=\sum_{i=1}^{n} y R_{\min }^{i} .
$$

Because of this guarantee, the fund is also constrained to maintain at all times and in all states a minimum capital $w_{\text {min }}$ which is the guaranteed capital accumulated by the current contributing generations. The solvency check is made at the beginning of the year, after pensions and dividends have been paid, but before contributions have been received. This means that if, for any reason, the fund has to interrupt its activities, the current market value of its assets would be enough to repay the contributions paid in the past by the currently active workers, in addition to a return $R_{\min }$ on these 
savings. This implies that $w_{\min }$ equals

$$
w_{\min }=\sum_{j=0}^{n-1}\left[\sum_{i=1}^{n-j} y R_{\min }^{i}\right]=\frac{y R_{\min }}{R_{\min }-1}\left(\frac{R_{\min }\left(R_{\min }^{n}-1\right)}{R_{\min }-1}-n\right) .
$$

The last equality holds only if $R_{\min }$ is not equal to unity. When $R_{\min }=1$, we simply have that $w_{\min }=y n(n+1) / 2$. In our benchmark calibration, we assume that the fund must guarantee a minimum return of $0 \%$ on the workers' contributions, i.e., $R_{\min }=1$. Combining this with $n=40$, we obtain that the minimum capital requirement is $w_{\min }=820 y$. The minimum benefit paid to retirees is $b_{\min }=40 y$.

We consider an economy in which a shareholder company manages the pension fund. Shareholders live forever and have an increasing and concave utility function $v$ on the dividends $d_{t}$ that are paid to them by the fund at the beginning of each year. To make things comparable with the first-best solution, we assume that shareholders have the same attitude towards risk as workers: $v \equiv u$. Because the shareholders' marginal utility tends to infinity when the dividend tends to zero, it is never efficient that shareholders bring more equity to the fund.

At date $t=0$, the new pension scheme is created and is funded with the combination of equity $e_{0}$ from shareholders and of initial contributions $Y_{0}$ from the $n$ generations of workers living at that time, so that $w_{0}=e_{0}+Y_{0}$. As in the previous section, we assume that $Y_{0}$ equals $1638 y$. There is a competition among insurers to determine who will manage the fund in the future. This implies that $v_{0}$ equals the expected utility that insurers can obtain by investing $e_{0}$ directly on financial markets, or that

$$
\begin{aligned}
v_{0} & =\max E\left[\sum_{t=0}^{\infty} \beta^{t} v\left(\widetilde{d}_{t}\right)\right] \\
\text { s.t. } \quad e_{t+1} & =R\left(e_{t}-d_{t}\right)+\alpha_{t} \widetilde{x}_{t}, \quad \forall t \geq 0 ; \\
e_{t} & \geq 0, \quad \forall t \geq 1 .
\end{aligned}
$$

¿From the previous section, we know that this problem has an analytical solution, yielding

$$
v_{0}=\frac{m^{-\gamma} e_{0}^{1-\gamma}}{1-\gamma}
$$


Given this shareholders' utility reservation level $v_{0}$, consider now the decision problem of the fund at the beginning of period 0 , given its financial reserves $w_{0}=e_{0}+Y_{0} \geq w_{\text {min }}$. We look for the dynamic contingent strategy of the fund, both in terms of distribution and portfolio management, that maximizes the welfare of the overlapping generations of workers, subject to the participation constraint (25) of the shareholders of the fund, the minimum benefit constraint, the solvency constraint and the no-borrowing constraint:

$$
\begin{aligned}
U^{s b} & =\max E\left[\sum_{t=0}^{\infty} \beta^{t} u\left(\widetilde{b}_{t}\right)\right] \\
\text { s.t. } \quad E\left[\sum_{t=0}^{\infty} \beta^{t} v\left(\widetilde{d}_{t}\right)\right] & \geq v_{0} ; \\
w_{0} & =Y_{0}+e_{0} \\
w_{t+1} & =R\left(w_{t}-b_{t}-d_{t}+n y\right)+\alpha_{t} \widetilde{x}_{t}, \quad \forall t \geq 0 ; \\
b_{t} & \geq b_{\min }, \quad \forall t \geq 0 ; \\
w_{t} & \geq w_{\min }, \quad \forall t \geq 0 ; \\
\alpha_{t} & \leq w_{t}-b_{t}-d_{t}+n y, \quad \forall t \geq 0 .
\end{aligned}
$$

This maximization program is well-behaved and has a feasible solution if $R$ is larger than $R_{\text {min }}$. The optimal solution is referred to as the secondbest strategy. Because this program has no analytical solution, we hereafter rely on a numerical algorithm to describe the second-best strategy. Using Mathematica ${ }^{\circledR}$, we solve the problem by backward induction using 200 iterations, starting from the first-best value function. In Table 1, we summarize the value of the exogenous parameters of the model.

\begin{tabular}{|l|l|l|}
\hline$\gamma$ & $=5$ & $:$ constant relative risk aversion of workers and shareholders; \\
\hline$\beta$ & $=0.9374$ & $:$ discount factor; \\
\hline$\widetilde{x}$ & & $:$ excess return of the risky asset $\left(E \widetilde{x}=3.9 \% ; \sigma_{x}=13.6 \%\right) ;$ \\
\hline$R$ & $=1.02$ & $:$ gross interest rate; \\
\hline$R_{\min }=1.00$ & $:$ gross guaranteed minimum return on contributions; \\
\hline$w_{\min }=820 y$ & $:$ minimum value of assets of the fund; \\
\hline$Y_{0}$ & $=1638 y$ & $:$ initial contribution of workers at $t=0 ;$ \\
\hline$e_{0}$ & & $:$ initial equity of the insurance company at $t=0$. \\
\hline
\end{tabular}

Table 1: Parameter values in the calibration 


\subsection{The allocation of risk between workers and share- holders}

For any positive scalar $\lambda$, define the function $\widehat{u}(. ; \lambda)$ as follows:

$$
\widehat{u}(c ; \lambda)=\max _{b} u(b)+\lambda v(c-b) \quad \text { s.t. } \quad b \geq b_{\min } .
$$

It is easily shown that $\widehat{u}(c ; \lambda)$ is increasing and concave in $c$, and that the solution $b(c ; \lambda)$ of this program is increasing in $c$. Moreover, it is immediate that we can rewrite program (24) as

$$
\begin{aligned}
U_{\lambda}^{s b}=\max _{c, \alpha} E\left[\sum_{t=0}^{\infty} \beta^{t} \widehat{u}\left(\widetilde{c}_{t} ; \lambda\right)\right] \\
\text { s.t. } \quad w_{0}=Y_{0}+e_{0} \\
w_{t+1}=R\left(w_{t}-c_{t}+n y\right)+\alpha_{t} \widetilde{x}_{t}, \quad \forall t \geq 0 ; \\
w_{t} \geq w_{\min }, \quad \forall t \geq 0 ; \\
\alpha_{t} \leq w_{t}-c_{t}+n y, \quad \forall t \geq 0,
\end{aligned}
$$

where $\lambda$ is selected in order to satisfy the shareholders' participation constraint (25) as an equality, i.e.,

$$
E\left[\sum_{t=0}^{\infty} \beta^{t} v\left(\widetilde{c}_{t}-b\left(\widetilde{c}_{t} ; \lambda\right)\right)\right]=v_{0} .
$$

Taking the initial equity $e_{0}$ and the induced shareholders' reservation level $v_{0}$ computed from (23), the natural methodology would be to find the $\lambda$ that solves (33). Because the solution of program (32) is itself a function $\lambda$, this would be a difficult problem to solve numerically. We reverse-engineered this strategy by solving program (32) with an arbitrary (but cleverly chosen) $\lambda$, and by computing the corresponding shareholders' reservation level $v_{0}$ using equation (33) and the initial equity level $e_{0}$ using equation (23).

By decomposing program (24) into programs (31) and (32), we disentangle the dynamic accumulation and risk-taking problem (32) of the fund from the purely static problem (31). Program (31) is a standard cake-sharing problem which determines how the total yearly payment $c$ of the fund in any 
given year should be shared between a benefit $b$ to workers and a dividend $d=c-b$ to shareholders. Because $u$ and $v$ exhibit the same constant relative risk aversion, the first-best risk sharing rule would be to allocate a fixed proportion $k \in[0,1]$ of the payment to workers: $\widetilde{b}_{t}=k \widetilde{c}_{t}$, with $k=\left(1+\lambda^{1 / \gamma}\right)^{-1}$. As explained above, we hereafter fix $k=90 \%$ (yielding $\lambda=1.69 \times 10^{-5}$ ), and we derive the corresponding equilibrium equity $e_{0}$ brought by shareholders when the fund is created. We obtain $e_{0}=356 y$. This is a relatively marginal amount compared to the initial funding by the existing generation, which was assumed to be $Y_{0}=1638 y$, and to the NPV $K=2040 y$ of future contributions.

The presence of the guaranteed minimum return of workers' contributions implies that the second-best risk-sharing rule between workers and shareholders takes the following form:

$$
\widetilde{b}_{t}=\max \left(b_{\min }, k \widetilde{c}_{t}\right) .
$$

The second-best contract offers a constant share $k$ of the total yearly payment of the fund to the retiring workers, as long as this pension benefit is larger than the guaranteed minimum $b_{\min }$. The dividend paid to shareholders equals $\widetilde{d}_{t}=\min \left(\widetilde{c}_{t}-b_{\min },(1-k) \widetilde{c}_{t}\right)$. It is noteworthy that the indirect utility function $\widehat{u}$ exhibits a constant relative risk aversion $\gamma=5$ as long as the minimum return constraint is not binding. When this constraint is binding, workers do not participate to the sharing of the portfolio risk, thereby raising the relative risk aversion of the syndicate. This relative risk aversion goes up to plus infinity when the total payment $c$ goes down to $b_{\min }$.

The shareholders of the fund thus provide portfolio insurance to the workers. They get a premium for this service. Indeed, their contribution $e_{0}=356 y$ represents only $8.82 \%$ of the total initial value of the fund, which is $e_{0}+Y_{0}+K=4034 y$. But they have a right on $10 \%$ of the distributed earnings, as long as the fund is financially healthy.

\subsection{The benefit policy and the dividend policy}

In this section, we examine the second-best strategy of benefit payment to the retiring generation. This benefit is a function of the level of financial reserves of the fund at the retirement date: $b_{t}=b^{s b}\left(w_{t}\right)$. We have seen that the firstbest benefit policy function was $b^{f b}(w)=0.0343 w+69.97$. In Figure 4 , we 
depicted the second-best benefit distributed to retiring workers as a function of $w$. When the market value of the assets of the company is approaching the minimum reserve level $820 y$, it is optimal to limit the benefit paid to the retiring workers to its minimum guaranteed level $b_{\min }=40 y$. Otherwise, the benefit is increasing and concave in $w$. For very large values of $w$, the second-best benefit converges to its first-best level. The second-best benefit is always smaller than its first-best level: $b^{s b}(w) \leq b^{f b}(w)$ for all $w$. The difference is particularly important when the fund's financial health is much deteriorated.

INSERT FIGURE 4 AROUND HERE

This illustrates the fact that the financial reserves of the fund are used as a buffer stock à la Deaton (1991) to organize the intergenerational sharing of risk. The level of the buffer stock must be well-enough enough above $w_{\text {min }}$ to make it feasible and efficient under the solvency constraint of the fund. This provides an additional incentive for the fund to reduce the distribution of benefits when $w$ is close to $w_{\text {min }}$. This reduction of the benefit paid by the fund in bad times is an effort made in the short run that is helpful to restore the efficiency of the fund in the long run.

The uncertainty about the pension benefits that the fund will pay in the future depends upon the time horizon under consideration. In Figure 5, we depicted the distribution of the benefits paid to the generation retiring respectively 40 and 60 years after the reform. These distributions were obtained by performing 10000 random simulations of 60 years of equity returns, starting with a fund's initial reserve equaling $Y_{0}+e_{0}$. The mean pension benefits are 106.2y and 107.5y for the population retiring in 40 and 60 years, respectively. The standard deviations are respectively $35.8 y$ and $44.5 y$.

\section{INSERT FIGURE 5 AROUND HERE}

The second-best strategy to distribute dividends to the shareholders of the insurance company is depicted in Figure 6. When the minimum return constraint is not binding, the second-best dividend equals $(1-k) / k=11.11 \%$ of the benefit paid to retiring workers, as explained in the previous section. When this constraint becomes binding, shareholders must drastically reduce their dividend. Because shareholders provide portfolio insurance to workers, they are highly exposed to the downside risk on the performance of the fund. In theory, it could be useful to ask shareholders to provide additional equity when the fund's financial health becomes critical. This is allowed in our model since we do not restrict the dividend to be positive. However, a 
negative dividend would not be renegotiation-proof. We escaped this problem by assuming that the utility function of the shareholders is CRRA, which implies that a negative dividend can never be optimal. This implies that shareholders contribute to the financing of the system only up-front, so that they always have the incentive to control the system. In addition, their exposure to the downside risk of the fund provides an additional incentive for the shareholders to efficiently manage the fund's assets.

INSERT FIGURE 6 AROUND HERE

\subsection{The investment policy}

The second-best investment in the risky asset in year $t$ is a function of the market value of the assets of the fund at that time: $\alpha_{t}=\alpha^{s b}\left(w_{t}\right)$. This optimal strategy is described in Figure 7. It should be compared to the first-best investment $\alpha^{f b}(w)=a^{*}(w+K)$, which is characterized by a constant share of the risky asset in the total wealth of the fund, including the market value $K$ of future contributions. Of course, this first-best strategy is not feasible in the second-best context, since the fund would take too much risk in a financially stressed situation. Following the first-best investment strategy would yield an important insolvency risk. The reduction of the risk exposure in these situations guarantees the solvency of the fund at the cost of a significant reduction in the expected performances of the fund's portfolio. The solvency constraint reduces the ability of the fund to time-diversify the portfolio risk, thereby making it more risk-averse at low wealth levels. It is as if the fund exhibited decreasing absolute risk aversion, as explained by Epstein (1983) and Gollier (2002).

INSERT FIGURE 7 AROUND HERE

In Figure 8, we have drawn the investment in the risky asset as a fraction of the financial reserves of the fund, not taking into account the NPV of future contributions. The first-best share $\alpha^{f b}(w) / w=a^{*}(w+K) / w$ is a decreasing hyperbola. Indeed, the fund should take into account of the flow of future contributions, which can be interpreted as a risk free asset in the fund's balance sheet. Therefore, at low levels of the financial reserves $w$, the fund should invest a relatively large fraction of its cash-in-hand, $w$, in the risky asset in order to compensate for the existence of this risk free asset in the fund's total wealth. This effect is diluted at larger levels of the fund's financial reserves. The second-best investment strategy $\alpha^{s b}(w) / w$ described 
in Figure 8 combines the solvency effect already exhibited in Figure 7 and the effect of the safe flow of future contributions. It has an inverse $\mathrm{U}$ shape with a maximum at $56 \%$ when the fund's reserves are around 2.5 times its minimum level. It tends to $a^{f b}=39.0 \%$ when the fund's reserves tends to infinity.

\section{INSERT FIGURE 8 AROUND HERE}

\subsection{The dynamics of reserves accumulation}

In the first-best solution, we have seen that the fund's level of financial reserves is a martingale in the sense that the growth of the fund's expected wealth is zero. The discount factor $\beta$ has been selected to obtain this property of the first-best solution. Two contradictory effects influence this rate in the second-best context. First, because the distribution of benefits to retirees is less generous $\left(b^{s b}(w)<b^{f b}(w)\right)$, the second-best fund accumulates reserves faster. This positive effect is particularly strong at low wealth levels. Second, the second-best investment strategy is more precautionary than the first-best one. This reduces the expected portfolio return of the fund. This negative effect on the rate of accumulation is also particularly strong at low wealth levels. In Figure 9, we have drawn the expected rate of increase of the fund's financial reserves as a function of $w$. We see that the second-best expected growth rate is always positive, but it tends to zero for high levels of reserves. When the financial health of the fund is much deteriorated, this rate can be as large as half of one percent per year. This illustrates the fund's willingness to escape the solvency problem that would inhibit intergenerational risk sharing.

\section{INSERT FIGURE 9 AROUND HERE}

In Figure 10, we have drawn the 5\%,50\% and 95\% percentiles of 60.000 simulated paths of the fund's reserve over the first 100 years of the fund. We already know that the expected level of the fund's reserve is constant over time. This figure tells us that the distribution of the fund's reserve is positively skewed. This is the consequence of the optimal investment and distribution strategies, in which the fund becomes extremely prudent when the fund's reserve tends toward its lower solvency limit.

INSERT FIGURE 10 AROUND HERE

Let us consider the effect of a negative excess return of $x=-10 \%$ of the risky asset on the flows generated by the fund. Suppose first that this 
negative shock occurs in year $t=0$, when $w=Y_{0}+e_{0}=1994 y$. From this, the fund paid $b_{0}=106.5 y$ to new retirees and $d_{0}=11.9 y$ to shareholders. Because it collected $40 y$ in contributions from workers, the fund's reserves amounted to $1915.6 y$, from which $\alpha^{s b}=1083 y$ has been invested in the risky asset. With a return of $-10 \%$ on this investment, the return of the fund's portfolio at the end of year $t=0$ is thus equal to $0.02(1915.6 y)-$ $0.1(1083 y)=-70 y$. The financial reserves at the beginning of the second year equal $w_{1}=1845.6 y$, a $7.44 \%$ reduction from the previous year. It yields a reduction of the pension benefit to the generation retiring at the beginning of year $t=1$ to $b_{1}=100.8 y$, a $5.35 \%$ reduction compared to the pension paid to the previous generation. The demand for the risky asset is reduced by $8.4 \%$. In Table 2, we computed these values when the adverse shock occurs in other circumstances. The net effect of the financial shock on the fund reserves is increasing in the market value of its assets. This illustrates the fact that the fund takes proportionally more portfolio risk at high wealth levels.

\begin{tabular}{|c|c|c|c|}
\hline & $w=1000 y$ & $w=1994 y$ & $w=3000 y$ \\
\hline$\Delta w / w$ & $-3.88 \%$ & $-7.44 \%$ & $-7.38 \%$ \\
\hline$\Delta b / b$ & $-4.90 \%$ & $-5.35 \%$ & $-5.36 \%$ \\
\hline$\Delta \alpha / \alpha$ & $-19.71 \%$ & $-8.40 \%$ & $-6.73 \%$ \\
\hline
\end{tabular}

Table 2: The short-term effect of a negative excess return $x=-10 \%$ on reserves $(\Delta w / w)$, pension benefits $(\Delta b / b)$ and the demand for stocks $(\Delta \alpha / \alpha)$. These short-term effects are evaluated for three different initial levels $w$ of the fund's reserves.

\subsection{Welfare analysis}

The discounted value of the flow of generational expected utilities at date $t=0$ equals $U^{s b}$. As before, we measure the certainty equivalent constant benefit $B^{s b}$ distributed to all future generations that yields the same intergenerational welfare: $U^{s b}=u\left(B^{s b}\right) /(1-\beta)$. We obtain $B^{s b}=94.8 y$. This is better than the certainty equivalent pension $B^{a u t}=84.1 y$ obtained in autarky, but much worse than the certainty equivalent pension $B^{f b}=108.8 y$ obtained in the first-best context. The second-best pension system improves welfare, but the constraints imposed on it imply that only $43 \%$ of the potential social surplus of intergenerational risk sharing. In terms of certainty 
equivalent return on savings, we obtain $r^{s b}=3.83 \%$, which is in between $r^{a u t}=3.33 \%$ and $r^{f b}=4.39 \%$.

An alternative approach consists in estimating the welfare of any specific generation conditional on the fund's reserves when this generation starts contributing to the pension fund. Parallel to what we have done in the firstbest context, we define the conditional certainty equivalent benefit $b^{s b}(w)$ as

$$
u\left(b^{s b}(w)\right)=E\left[u\left(\widetilde{b}_{t+n}\right) \mid w_{t}=w\right] .
$$

The right-hand side of this equality can be numerically estimated by using backward induction. The outcome of these computations is depicted in Figure 11. We see that $b^{s b}(w)$ is smaller than $b^{f b}(w)$ for all $w$. This means that the second-best fund is less attractive than the first-best fund for new workers at all reserves levels, because of the inefficient intergenerational risk sharing. We also see that new workers prefer to save on their own when the fund's reserves at the time of their first contribution is less than $w^{\text {sus }}=1905 y .{ }^{12}$ This is called the "minimum sustainable reserve". Notice that the initial reserve $Y_{0}+e_{0}=1994 y$ exceeds the minimum sustainable reserve, so that the fund is attractive for the founding generations. However, there is no guarantee that the fund's assets value will permanently remain above $w^{\text {sus }}$. If the participation in the fund is on a voluntary basis, when $w_{t}$ is less than $w^{\text {sus }}$, the new generation entering in year $t$ would not accept to contribute to the fund unless a tax incentive for long-term savings is offered. For example, in the most critical situation with $w_{t}=1000 y$, the certainty equivalent benefit distributed by the second-best fund is equal to $b^{s b}(1000 y)=59.1 y$, which is $29 \%$ smaller than the certainty equivalent benefit obtained in autarky. A tax incentive of this order would be necessary to make the second-best pension scheme sustainable.

INSERT FIGURE 11 AROUND HERE

\section{Sensitivity analysis}

In this section, we perform some sensitivity analyses of the second-best pension scheme. The parameters of the model are $\beta$ (the discount factor), $R_{\text {min }}$ (the guaranteed minimum gross return), $R$ (the risk-free rate), $\widetilde{x}$ (the

\footnotetext{
${ }^{12}$ Notice that $w^{\text {sus }}$ is defined by $u\left(b^{s b}\left(w^{s u s}\right)\right)=U^{a u t}$.
} 
distribution of the stock returns), $\gamma$ (relative risk aversion), and $e_{0}$ (the initial equity). As explained in section 5.2, there is a one-to-one relationship between $e_{0}$ and $v_{0}$ (equation (23), and between $v_{0}$ and the share $k$ of the yearly payment of the fund that is allocated to the retiring generation, with the remaining $1-k$ being paid to shareholders. Numerically speaking, it is much easier to fix $k$ as an exogenous choice variable, and to derive on the $e_{0}$ that is compatible with this $k$ at equilibrium. We have seen earlier that our benchmark initial equity $e_{0}=100 y$ is compatible with the distribution of $k=90 \%$ of the yearly fund's payment to workers. In our sensitivity analysis, we fix $k=90 \%$ and we select the initial equity $e_{0}$ that is compatible with this $k$. Table 3 summarize our findings. The different lines of this table are self-explanatory, except the line referred to as $E\left(w_{t+1}-w_{t}\right) / w_{t}$. As seen in Figure 9, the expected yearly change in the fund's assets value depends upon the state variable $w$. On this line, we report its asymptotic value $R(1-m)\left[1+a^{*} E \widetilde{x}\right]-1$.

\begin{tabular}{|c|c|c|c|c|c}
\hline & $\begin{array}{c}\text { Second } \\
\text { best } \\
\text { benchmark }\end{array}$ & $\begin{array}{c}\beta=0.937 \\
\downarrow=0.9\end{array}$ & $\begin{array}{c}R_{\min }=100 \% \\
R_{\min }=90 \%\end{array}$ & $\begin{array}{c}k=90 \% \\
\downarrow \\
k=80 \%\end{array}$ & $\begin{array}{c}\widetilde{x} \\
\downarrow \\
\tilde{x}-1 \%\end{array}$ \\
\hline $\begin{array}{c}\text { certainty equivalent return } \\
r^{s b}\end{array}$ & $3.83 \%$ & $4.09 \%$ & $4.07 \%$ & $3.91 \%$ & $3.37 \%$ \\
\hline $\begin{array}{c}\text { initial reserve } \\
Y_{0}+e_{0}\end{array}$ & $1994 y$ & $1968 y$ & $2015 y$ & $2455 y$ & 1723 \\
\hline $\begin{array}{c}\text { initial risky investment } \\
\alpha_{0}\end{array}$ & $1083 y$ & $970 y$ & $1290 y$ & $1332 y$ & $798 y$ \\
\hline $\begin{array}{c}\text { initial pension benefit } \\
b_{0}\end{array}$ & $106.5 y$ & $120.6 y$ & $114.6 y$ & $109.7 y$ & $85.3 y$ \\
\hline $\begin{array}{c}\text { initial dividend } \\
d_{0}\end{array}$ & $0 \%$ & $-0.8 \%$ & $0 \%$ & $0 \%$ & $0 \%$ \\
\hline $\begin{array}{c}\text { FB growth rate of reserve } \\
E\left(w_{t+1}-w_{t}\right) / w_{t}\end{array}$ & $1905 y$ & $2198 y$ & $1728 y$ & $2281 y$ & 1619 \\
\hline $\begin{array}{c}\text { min sustainable reserve } \\
w^{\text {sus }}\end{array}$ & $1.9 y$ & $12.7 y$ & $27.4 y$ & $9.5 y$ \\
\hline
\end{tabular}

Table 3: Effect of a reduction of the discount factor $\beta$, of a reduction of the guaranteed gross return $R_{\min }$, of a reduction of the share $k$ of the fund's total yearly payment accruing to retirees, and of a leftward translation of 
the distribution of excess returns $\widetilde{x}$.

- Reduction of $\beta$ from 0.9374 to 0.9 : The current generations are favored by this reduction of the discount factor. The benefit paid to the retiring workers during the first year of the fund is increased, together with the dividend paid to shareholders. Because risks are less efficiently allocated across generations, the fund reduces its exposure to portfolio risk. All these changes converge towards the fact that the expected yearly change in the fund's assets value be reduced with respect to the benchmark. In fact, the expected change becomes negative. Financial reserves converge in expectation to $w_{\min }$. Because of its generous benefits paid early to retiring workers, the fund is beneficial for intergenerational risk sharing only in the short and medium terms. In the long term, the financial reserves of the fund cannot be used as a buffer stock to smooth shocks across generations, because of the solvency constraint.

- Reduction of $R_{\text {min }}$ from $100 \%$ to $90 \%$ : Reducing the guaranteed minimum return on savings is good for the intergenerational sharing of risks. This change has a sizeable impact on the certainty equivalent return of the pension scheme. Because shareholders are less exposed to the downside financial risk, the equilibrium initial equity $e_{0}$ is increased. The optimal portfolio risk exposure is also increased, because this risk is shared more efficiently with future generations. This yields an increase in the benefits paid to new retirees and to shareholders.

- Reduction of $k$ from $90 \%$ to $80 \%$ : Increasing the share of the fund's portfolio return accruing to shareholders raises the equilibrium equity initially invested in the fund by shareholders. Because the initial value of the fund's assets is much above the legal minimum to satisfy the solvency constraint, the fund is in a better situation to organize an efficient intergenerational risk sharing. The certainty equivalent return on savings is thereby improved compared to the benchmark. The share of the fund's assets invested in stocks, the benefit paid to new retirees and the dividend paid to shareholders are all increased.

- Deterministic reduction of stocks returns by $1 \%$ : This change in expectations dramatically reduces both the investment in the risky asset 
and the certainty equivalent return on savings. Because of the reduced return on savings, the willingness to accumulate wealth over time is reduced. In fact, a decumulation process arises under these values of the parameters, as in the case of the reduction of $\beta$. Notice that this translation of the distribution of excess returns also affects the workers' welfare in autarky, yielding a reduction of the certainty equivalent pension wealth to $B^{a u t}=73.2 y$, and of the certainty equivalent interest rate to $r^{\text {aut }}=2.75 \%$.

\section{Concluding Remarks}

The aims of this paper were twofold. First, we wanted to characterize operational rules for a pension fund to optimize both the sharing of risk across generations and the dynamic portfolio management of this fund. We showed that both the asset allocation of the fund and the promised pension benefits should be contingent upon the fund's assets to liabilities ratio. The target share of the fund's assets to be invested in equity should be around 40 and $50 \%$, but this share should be drastically reduced when the financial health of the fund deteriorates. The target share of the fund's reserves to be distributed as pension benefits should be around 3.5\%, but this share of pension benefit distributed to retirees should go down to the minimum guaranteed level when the solvency constraint becomes an issue.

Second, we wanted to estimate the welfare gain of intergenerational risk sharing. Compared to a purely individual retirement system, we showed that organizing a first-best intergenerational risk-sharing scheme has an effect on the welfare of all current and future generations that is equivalent to an increase by more than 1 percentage point in the return on their retirement savings. However, this welfare gain is halved when solvency constraints are imposed to the pension fund to reinforce the long-term political sustainability of the scheme.

Many proponents of the preservation of the PAYG system argue that this system, contrary to a funded system, is able to implement an efficient intergenerational sharing of risk. Contrary to this view, we have shown in this paper that a cleverly built, transparently funded system can do much to bolster the risk-sharing efficiency of a limited public intervention program. Our work is also useful to refine an argument long used by proponents of 
radical changes in social security schemes. According to their view, the PAYG system should be abolished due to its low rate of return. The problem is to determine to which rate of return of the funded system should it be compared. If it is compared to the real risk-free rate, which has been around $1.5 \%$ in the U.S. and around $-1 \%$ in France during the twentieth century, ${ }^{13}$ the argument is not very strong. If it is compared to the average real return on equity, which has been around respectively $7 \%$ and $4 \%$ in the U.S. and in France, the argument would be much stronger. Some proponents of the funded system claim that this alternative comparison is the relevant one, because of the ability of the pension fund to time-diversify equity risk. Using a calibration based on U.S. financial data, we have shown that this argument is only partially true, and that the implementation of the realistic second-best pension scheme has a certainty equivalent rate of return around $4.4 \%$.

This paper attempts to provide a realistic estimation of the welfare gains of intergenerational risk sharing. However, to make the model tractable, we made several simplifications compared to real pension schemes. Therefore, the paper could obviously be improved in many directions. First, we assumed that the risk-free rate is constant over time and that future stocks returns are unpredictable. We recognize that these two assumptions are important, but quite unrealistic. Long term financial intermediaries are very sensitive to the interest rate risk and this should be treated formally in a future extension of this work. Introducing predictable changes in the two assets returns will make the second-best benefit policy function dependent on the additional state variables of the system, in particular on the current interest rate. The pension benefit policy function and the optimal management of the fund's assets will be sensitive to changes in these additional state variables. Second, we considered for simplicity a defined contribution scheme. It would be useful to see how a more flexible contribution rule would be useful for a better sharing of risk over time. We should also take into account the diversity of tastes and preferences (that are affected by the number of dependants) among the consumers, as well as the possibility of premature death. Third, one could consider more sophisticated portfolio insurance rules, such as the one consisting in "locking in" successive benefits to active members of the fund. This would be a third-best approach.

\footnotetext{
${ }^{13}$ For a synthesis of financial returns during the last century, see Dimson, Marsh and Staunton (2000).
} 


\section{References}

Aaron, H., A. Blinder, A. Munnell and P. Orzag, (2000), Governor Bush's individual account proposal, mimeo, Brookings Institution.

Ball, L., and N.G. Mankiw, (2001), Intergenerational risk sharing in the spirit of Arrow, Debreu, and Rawls, with applications to social security design, Harvard Institute of Economic Research DP 1921.

Bodie, Z., R.C. Merton and W.F. Samuelson, (1992), Labor supply flexibility and portfolio choice in a life cycle model, Journal of Economic Dynamics and Control, 16, 427-449.

Bohn, H., (2003), Intergenerational risk sharing and fiscal policy, working paper, University of California at Santa Barbara.

Burtless, G., (2000), Social security privatization and financial market risk: Lessons from U.S. financial history, mimeo, Brookings Institution.

Teulings, C.N. and Vries, C.G. de, (2006), General accounting, solidarity and pension losses. De Economist, 154 (1), 63-83.

Cui, J., F. de Jong, and E. Ponds, (2005), The value of intergenerational transfers within funded pension schemes, working paper, University of Amsterdam.

Deaton , A., (1991), Saving and liquidity constraints, Econometrica, 59, 1221-48.

de Menil, G., F. Murtin, and E. Sheshinsky, (2006), Planning for the optimal mix of paygo tax and funded savings, 5, 1-25.

Demange, G., (2002), On the optimality in intergenerational risk sharing, Economic Theory, 20, 1-27.

Demange, G., and G. Laroque, (1999), Social security and demographic shocks, Econometrica, 67, 527-542.

Diamond, P., (1977), A framework for social security analysis, Journal of Public Economics, 8, 275-298. 
Dimson, E., P. Marsh and M. Staunton, (2000), The Millenium book: A century of investment returns, ABN-AMRO, Londres.

Epstein, L.G., (1983), Decreasing absolute risk aversion and utility indices derived from cake-eating problems, Journal of Economic Theory, 29, 245-64.

Gollier, C., (2002), Time diversification, liquidity constraints, and decreasing aversion to risk on wealth, Journal of Monetary Economics, 49, 1439-1459.

Gollier, C., (2005), Optimal portfolio management for individual pension plans, working paper, University of Toulouse.

Gordon, R.H., and H.R. Varian, (1988), Intergenerational risk sharing, Journal of Public Economics, 37, 185-202.

Grossman, S. and J.L. Vila, (1992), Optimal investment strategies with leverage constraints, Journal of Financial and Quantitative Analysis.

Krueger, D., and F. Kubler, (2006), Improving social security reform when financial markets are incomplete, American Economic Review, June issue.

Merton, R.C., (1969), Lifetime portfolio selection under uncertainty: The continuous- time case, Review of Economics and Statistics, 51, pp. 247-257.

Poterba, J., J. Rauh, S. Venti and D. Wise, (2003), Utility evaluation of risk in retirement saving accounts, NBER working paper, 9892.

Samuelson, P.A., (1963), Risk and uncertainty: the fallacy of the Law of Large Numbers, Scientia, 98, 108-113.

Samuelson, P.A., (1969), Lifetime portfolio selection by dynamic stochastic programming, Review of Economics and Statistics, 51, 239-246.

Shiller, R.J., (1999), Social security and institutions for intergenerational, intragenerational and international risk sharing, 
Carnegie-Rochester Conference Series on Public Policy, vol. 50, 165-204.

Shiller, R.J., (2003), The new financial order: Risk in the 21st century, Princeton NJ: Princeton University Press.

Valdés-Prieto, S. (2005), Securitization of taxes implicit in PAYG pensions, Economic Policy, vol. 20 (42).

van Hemert, O., (2005), Optimal intergenerational risk sharing, mimeo, University of Amsterdam. 


\section{Appendix 1: Proof of Proposition 1}

By backward induction, we can rewrite program (5) as

$$
v_{t}(w)=\max _{\alpha} E v_{t+1}(R(w+y)+\alpha \widetilde{x}),
$$

for $t=1, \ldots, n$, together with $v_{n+1}(w)=w^{1-\gamma} /(1-\gamma)$ and $U^{\text {aut }}=v_{1}(0)$. The solution $\alpha_{t}$ of this program is a function $\alpha_{t}(w)$ of the single state variable $w$. Let us consider the trial solution function $v_{t+1}(w)=K_{t+1}\left(w+h_{t+1}\right)^{1-\gamma} /(1-$ $\gamma$ ), for some positive scalar $K_{t+1}$ and where $h_{t}=\sum_{i=0}^{n-t} R^{-i} y$. Notice that it implies that

$$
\begin{aligned}
v_{t+1}(R(w+y)+\alpha \widetilde{x}) & =K_{t+1} \frac{\left(R(w+y)+\alpha \widetilde{x}+h_{t+1}\right)^{1-\gamma}}{1-\gamma} \\
& =K_{t+1} \frac{\left(R\left(w+h_{t}\right)+\alpha \widetilde{x}\right)^{1-\gamma}}{1-\gamma}
\end{aligned}
$$

The first-order condition for the above program can thus be written as

$$
K_{t+1} E\left[\widetilde{x}\left(R\left(w+h_{t}\right)+\alpha_{t}(w) \widetilde{x}\right)^{-\gamma}\right]=0 .
$$

It is immediate that this is true only when $\alpha_{t}(w)=a^{*} R\left(w_{t}+h_{t}\right)$ where $a^{*}$ solves $E \widetilde{x}\left(1+a^{*} \widetilde{x}\right)^{-\gamma}=0$. It implies in turn that

$$
\begin{aligned}
v_{t}(w) & =K_{t+1} E\left[\frac{\left(R\left(w+h_{t}\right)+R\left(w+h_{t}\right) a^{*} \widetilde{x}\right)^{1-\gamma}}{1-\gamma}\right] \\
& =\delta K_{t+1} \frac{\left(w+h_{t}\right)^{1-\gamma}}{1-\gamma}
\end{aligned}
$$

where $\delta=R^{1-\gamma} E\left(1+a^{*} \widetilde{x}\right)^{1-\gamma}$. Thus, our trial solution is correct, with $K_{t}=$ $\delta K_{t+1}$. This implies that

$$
\begin{aligned}
U^{a u t} & =v_{1}(0)=K_{1} \frac{h_{1}^{1-\gamma}}{1-\gamma} \\
& =\delta^{n} \frac{h_{1}^{1-\gamma}}{1-\gamma} .
\end{aligned}
$$

This completes the proof of Proposition 1. 


\section{Appendix 2: Proof of Proposition 2}

The proof of this proposition is similar to the proof of Proposition 1. By backward induction, we can rewrite program (12) as

$$
v(w)=\max _{b, \alpha} u(b)+\beta E v(R(w-b+n y)+\alpha \widetilde{x}) .
$$

Let us consider the trial solution function $v(w)=q(w+K)^{1-\gamma} /(1-\gamma)$, for some positive scalar $q$. Notice that it implies that

$v(R(w-b+n y)+\alpha \widetilde{x})=q \frac{(R(w-b+n y)+\alpha \widetilde{x}+K)^{1-\gamma}}{1-\gamma}=q \frac{(R(w-b+K)+\alpha \widetilde{x})^{1-\gamma}}{1-\gamma}$

The first-order conditions for the above program can thus be written as

$$
u^{\prime}(b)=\beta R q E\left[(R(w-b+K)+\alpha \widetilde{x})^{-\gamma}\right],
$$

and

$$
q E\left[\widetilde{x}(R(w-b+K)+\alpha \widetilde{x})^{-\gamma}\right]=0 .
$$

It is easy to check that $b(w)=\widehat{m}(w+K)$ and $\alpha(w)=a^{*} R(1-\widehat{m})(w+K)$ solves this system, with $\widehat{m}=\left(k q^{1 / \gamma}+1\right)^{-1}$ and $k=\left(\beta R^{1-\gamma} E\left(1+a^{*} \widetilde{x}\right)^{-\gamma}\right)^{1 / \gamma}$. Replacing the functions appearing in the following equality

$$
v(w)=u(b(w))+\beta E v(R(w-b(w)+K)+\alpha(w) \widetilde{x})
$$

by their expressions assumed above, we obtain that

$$
q=\widehat{m}^{1-\gamma}+\beta q R^{1-\gamma}(1-\widehat{m})^{1-\gamma} E\left(1+a^{*} \widetilde{x}\right)^{1-\gamma} .
$$

Because $E\left(1+a^{*} \widetilde{x}\right)^{1-\gamma}=E\left(1+a^{*} \widetilde{x}\right)^{-\gamma}$, this equation can be rewritten as

$$
\begin{aligned}
q & =\left(k q^{1 / \gamma}+1\right)^{\gamma-1}+k^{\gamma} q\left(\frac{k q^{1 / \gamma}}{k q^{1 / \gamma}+1}\right)^{1-\gamma} \\
& =\left(k q^{1 / \gamma}+1\right)^{\gamma-1}\left[1+k q^{1 / \gamma}\right]=\left(k q^{1 / \gamma}+1\right)^{\gamma} .
\end{aligned}
$$

It implies that $q=m^{-\gamma}$ and $m=\widehat{m}$. Thus, our trial solution is correct. This implies that

$$
U^{f b}=v\left(Y_{0}\right)=q \frac{\left(Y_{0}+K\right)^{1-\gamma}}{1-\gamma}=m^{-\gamma} \frac{\left(Y_{0}+K\right)^{1-\gamma}}{1-\gamma} .
$$


Finally, we have that

$$
\begin{aligned}
E\left[w_{t+1}+K\right] & =R\left(w_{t}-b_{t}+n y\right)+\alpha_{t} E \widetilde{x}+K \\
& =R\left(w_{t}+K\right)-R m\left(w_{t}+K\right)+R(1-m) a^{*} \mu\left(w_{t}+K\right) \\
& =R(1-m)\left[1+a^{*} \mu\right]\left(w_{t}+K\right) .
\end{aligned}
$$

This completes the proof of Proposition 2.

\section{Appendix 3: Numerical method to characterize the second-best solution}

In order to characterize the second-best solution, we proceed numerically by backward induction. We first fix the share $k$ of the total annual payment accruing to retirees. This yields the associated $\lambda=((1-k) / k)^{\gamma}$ and the indirect utility function $\widehat{u}$ defined by equation (31). This eliminates the risk sharing aspect of the problem between shareholders and workers. The remaining problem to solve is program (32). It can be rewritten as

$$
V(w)=\max _{c, \alpha} \widehat{u}(c)+\beta E V(R(w-c+n y)+\alpha \widetilde{x})
$$

subject to $w \geq w_{\min }$ and $\alpha \leq w-c+n y$. We consider its dynamic version:

$$
V_{t}(w)=\max _{c, \alpha} \widehat{u}(c)+\beta E V_{t+1}(R(w-c+n y)+\alpha \widetilde{x})
$$

subject to the same constraints. We start with the initial value function borrowed from the first-best solution:

$$
V_{T}(w)=\frac{m^{-\gamma} w^{1-\gamma}}{1-\gamma} .
$$

Using this specification, we numerically solve program (36) for $t=T-1$. We discretize $w$ in interval $\left[w_{\min }, 20 w_{\min }\right]$ by step $\Delta w=w_{\min } / 1000$. For each of the corresponding $w$, we solve program (36), and we obtain $V_{T-1}(w)$. We use this value function to solve this program for $t=T-2$. We iterate this process 150 times. It converges if $\beta$ is small enough.

During this procedure, we compute the discounted expected utility of both pension benefits and dividends, as functions of the fund's reserve. At the end of this converging process, we compute the initial equity $e_{0}$ which equalizes $v_{0}$ to the discounted expected utility of the flow of dividends, given the initial reserve $Y_{0}+e_{0}$. 


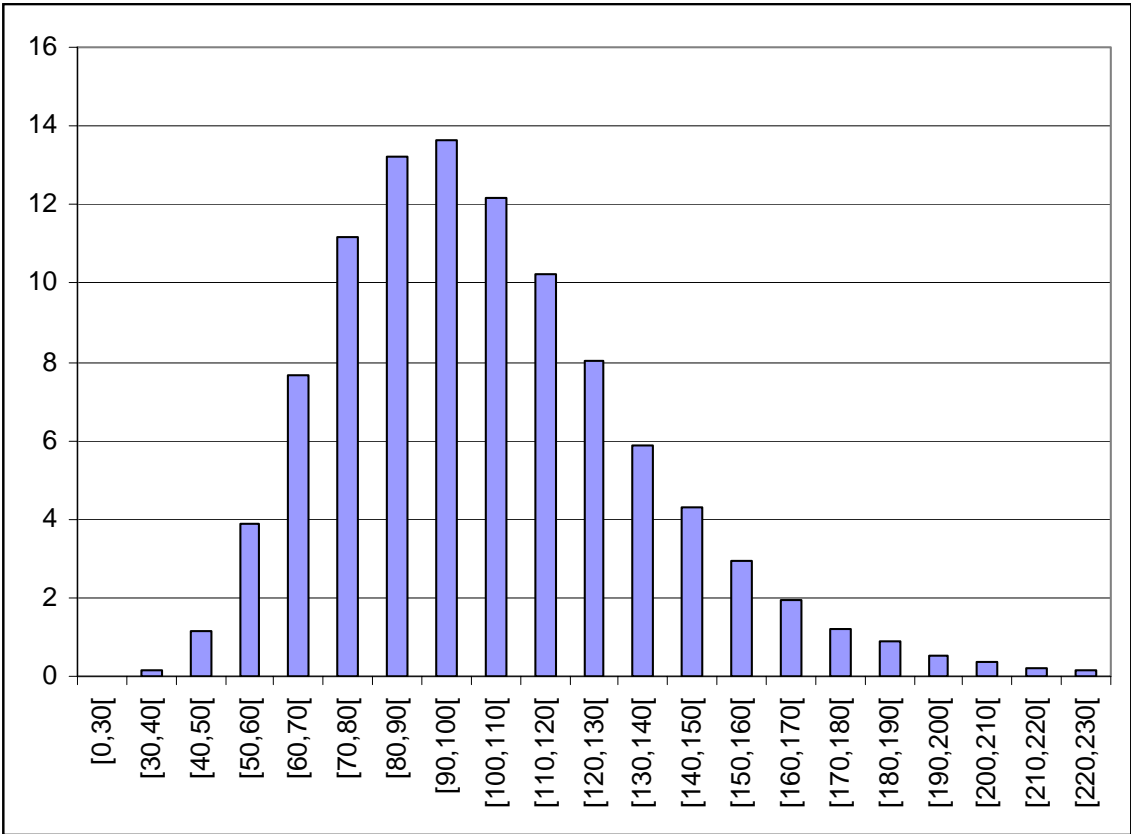

Figure 1: Frequency (in \%) of final pension benefits $b=w_{n+1}$ in autarky.

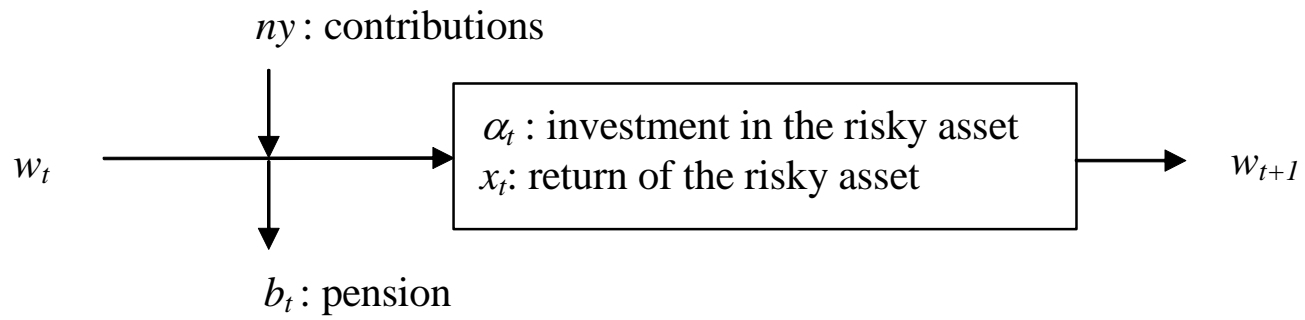

Figure 2: Financial flows in year $t$. 


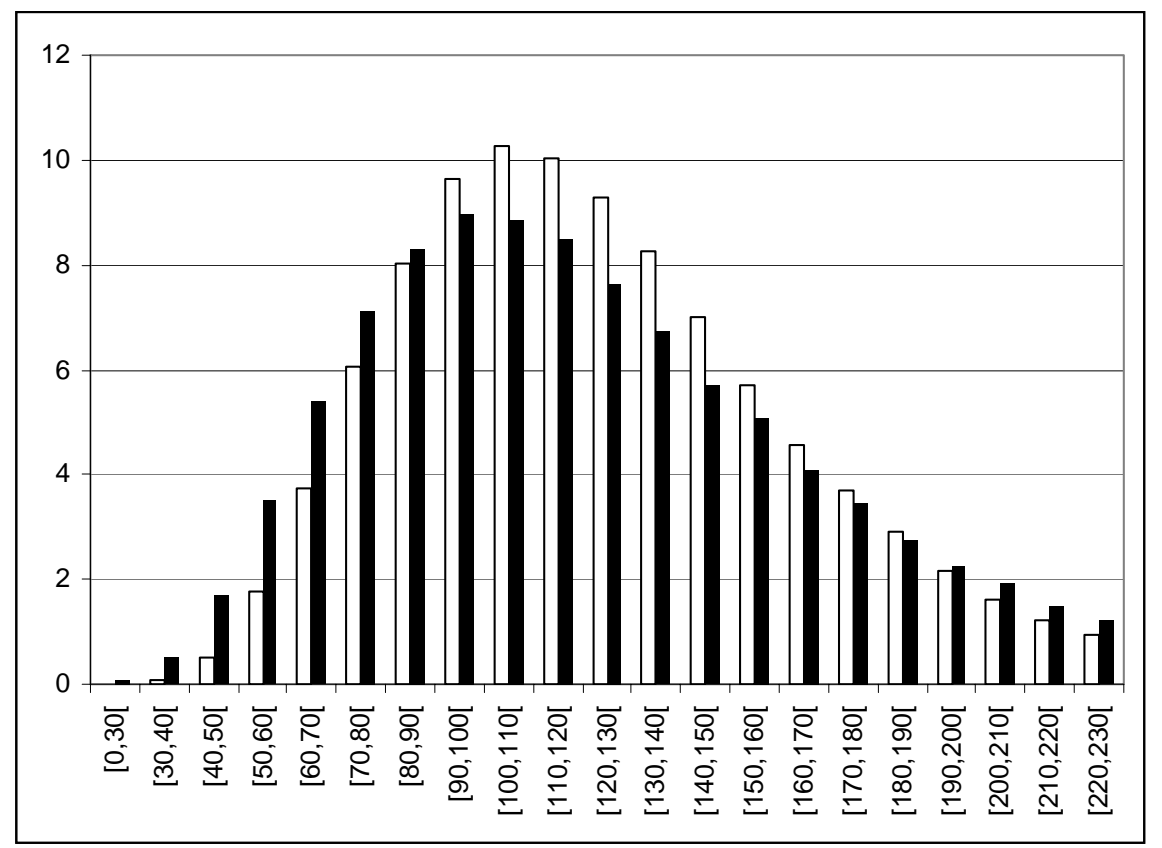

Figure 3: Frequency (in \%) of final pension benefits $\widetilde{b}_{t}^{f b}$ under the first-best pension mechanism. The white and black bars are for people retiring $t=40$ and $t=60$ years after the reform, respectively. 


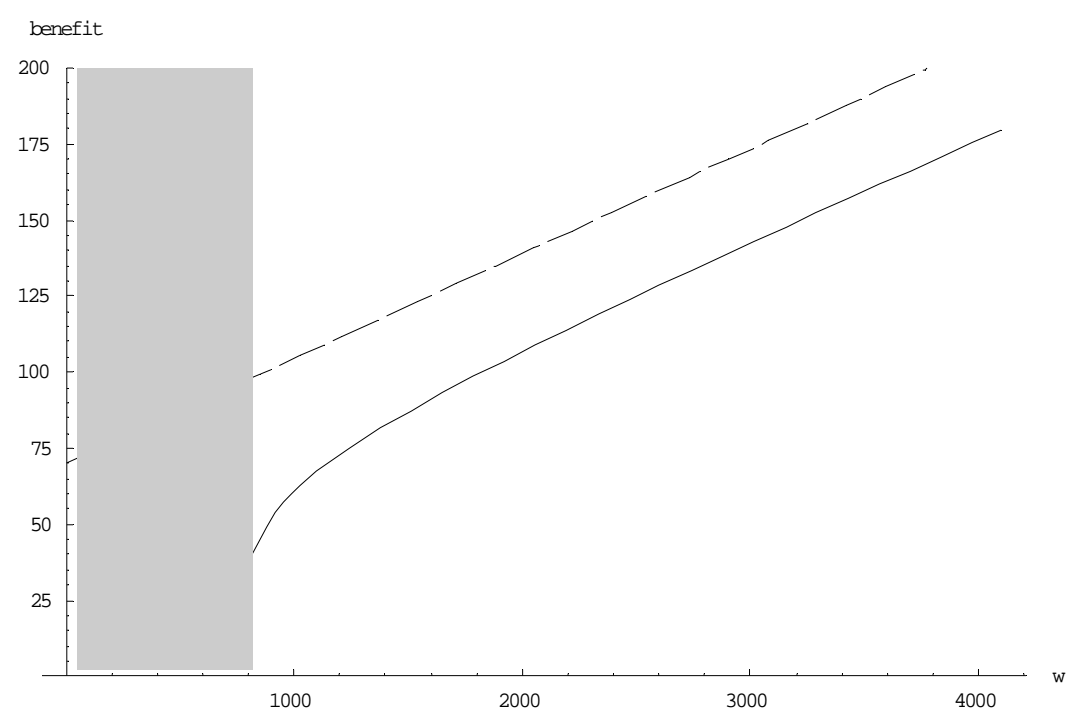

Figure 4: The first-best pension benefit (dashed) and the second-best pension benefit (plain) as a function of the fund's reserve $w$. The shaded rectangle correspond to the minimum reserve constraint $w \geq w_{\min }=820$. 


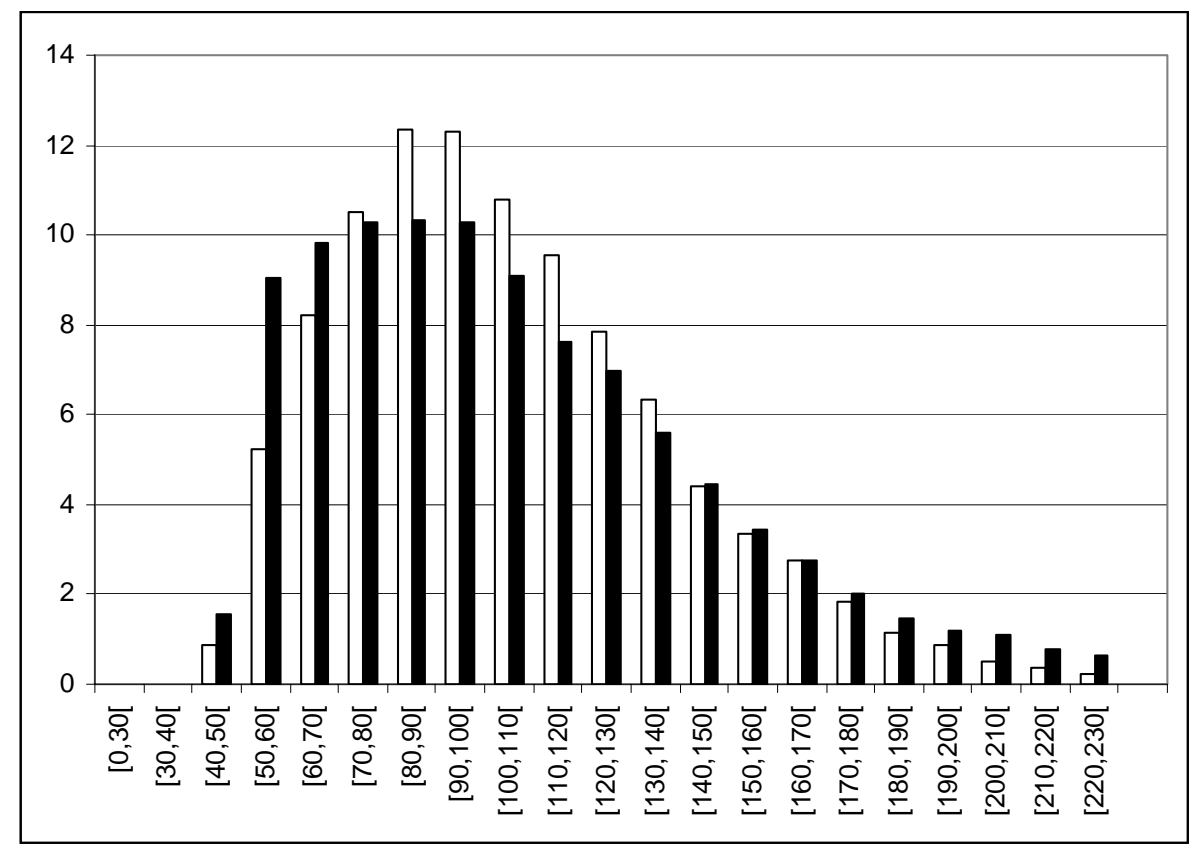

Figure 5: Frequency (in \%) of final pension benefits $b_{t}^{s b}$ under the second-best pension mechanism. The white and black bars are for people retiring $t=40$ and $t=60$ years after the reform, respectively. 


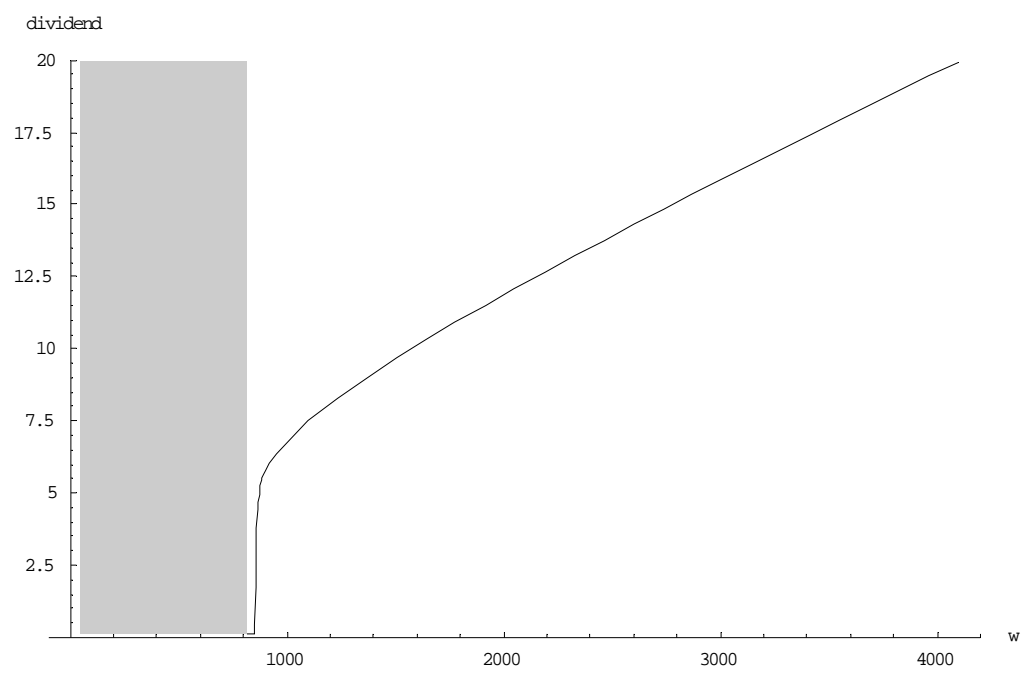

Figure 6: The second best dividend paid to the fund's shareholders as a function of the fund's reserve $w$.

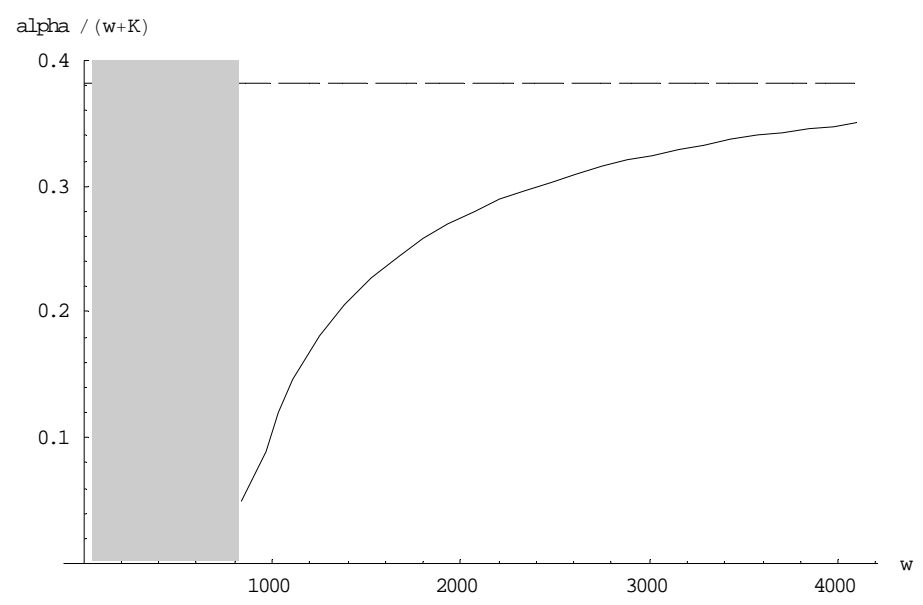

Figure 7: The second-best investment in the risky asset expressed as a fraction of the total wealth of the fund $w+K$. The dashed line describes the first-best investment strategy. 


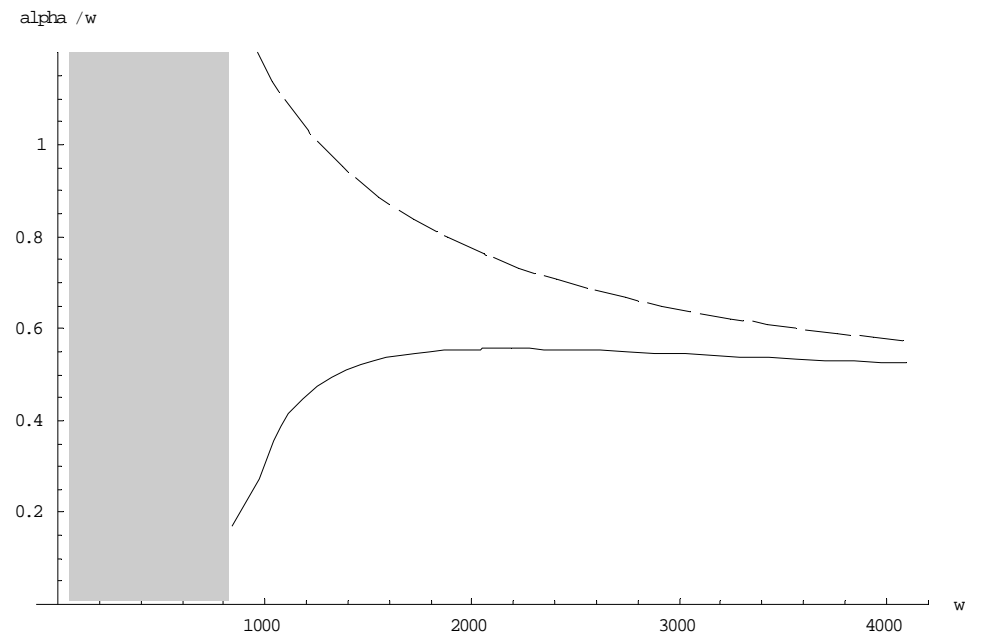

Figure 8: The second-best share of the fund's reserve $w$ invested in the risky asset, as a function of $w$. The dashed curve describes the first-best strategy.

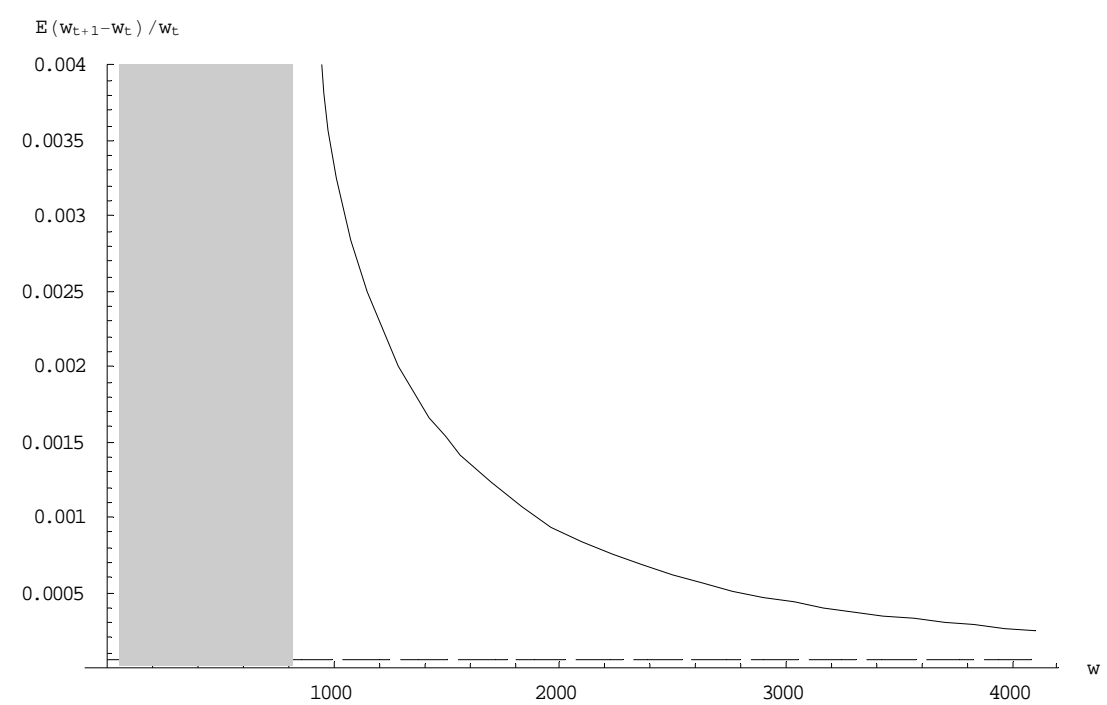

Figure 9: The expected yearly rate of increase of reserves as a function of the fund's reserve, in the second-best context. 


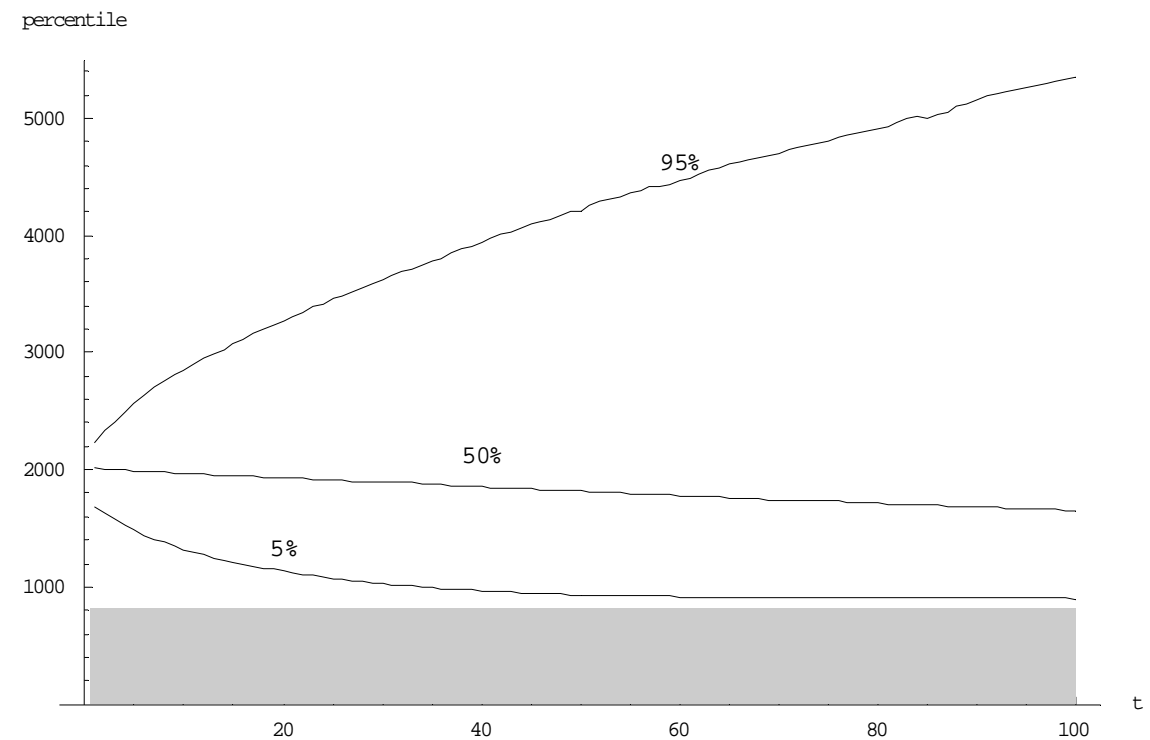

Figure 10: The 5\%,50\% and $95 \%$ percentiles of 60.000 simulated paths of the fund's reserve $w$ over the first 100 years of the fund, in the second-best context. 


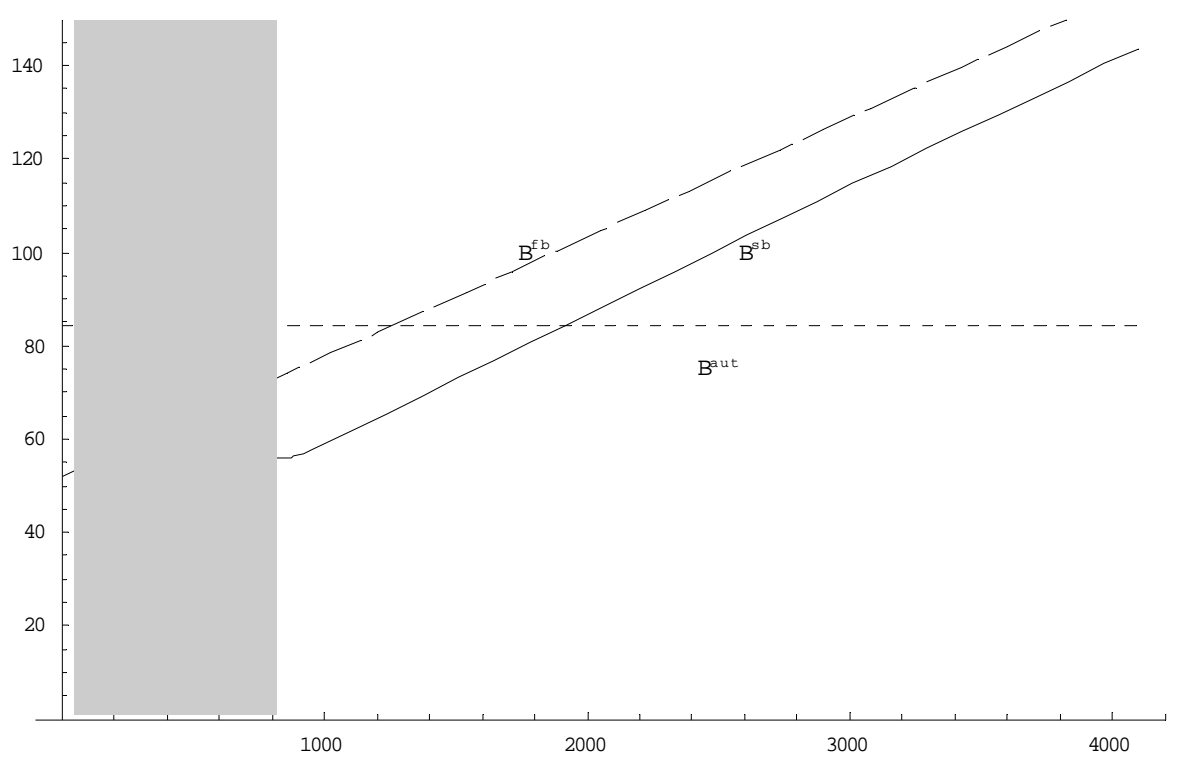

Figure 11: The certainty equivalent benefit $b$ conditional to the fund's reserve $w$ at the beginning of the worker's contribution period, for the first-best, second-best and autarky contexts. 